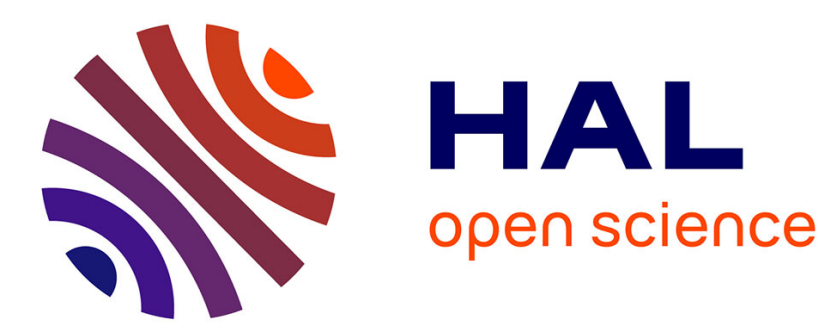

\title{
Soil-structure interaction for moving loads: application to railway traffic
}

Donatien Le Houedec, Gaëlle Lefeuve-Mesgouez, Benoit Picoux

\section{To cite this version:}

Donatien Le Houedec, Gaëlle Lefeuve-Mesgouez, Benoit Picoux. Soil-structure interaction for moving loads: application to railway traffic. Progress in Civil and Structural Engineering Computing, SaxeCoburg Publications, pp.315-344, 2003, 10.4203/csets.10.12 . hal-01007544

\section{HAL Id: hal-01007544 https://hal.science/hal-01007544}

Submitted on 5 Nov 2017

HAL is a multi-disciplinary open access archive for the deposit and dissemination of scientific research documents, whether they are published or not. The documents may come from teaching and research institutions in France or abroad, or from public or private research centers.
L'archive ouverte pluridisciplinaire HAL, est destinée au dépôt et à la diffusion de documents scientifiques de niveau recherche, publiés ou non, émanant des établissements d'enseignement et de recherche français ou étrangers, des laboratoires publics ou privés. 


\title{
SOIL-STRUCTURE INTERACTION FOR MOVING LOADS : APPLICATION TO RAILWAY TRAFFIC
}

\author{
D. LE HOUÉDEC, G. LEFEUVE-MESGOUEZ and B. PICOUX \\ Laboratory of Mechanics and Materials, Ecole Centrale de Nantes, Nantes, France.
}

\section{Keywords}

Soil-structure interaction - Wave propagation - Moving loads - Railway traffic - Numerical simulation

\begin{abstract}
The problem of determining the response of a soil medium under the action of moving loads has received considerable attention in the past. Work in this area has been motivated by the need to determine the vibratory motion on the ground surface and at depth caused by moving vehicles. Moreover, high-speed trains are becoming increasingly popular and freight trains increasingly heavier. Combined with this fact and the observation that Rayleigh wave speeds are slower in soft soils, we see that the study of moving loads is important for environmental and geotechnical engineers.

A lot of models are possible for the simulation of propagation phenomena. First, we can consider the case of a two-dimensional problem involving a moving harmonic strip load. The results derived by Fourier transform are valid for any frequency and load speed. For moving loads, to choose a suitable damping model, an original modified hysteretic damping is employed. Also, it is possible to investigate the transmission of vibrations due to a moving harmonic train of rectangular loads rigidly attached to an elastic multilayered ground. In this case, the previous damping model is used, combined with a dynamic stiffness matrix approach. In the spatial wavenumber domain, the dominant features encountered in a spectral decomposition corresponding to compression, shear and Rayleigh waves are illustrated. Also, results of the model at certain critical load speeds can be presented in dimensionless parameters.

For 3D problems, a three-dimensional semi-analytic model of ground vibration due to a moving harmonic rectangular load can be developed. The model consists of a half-space, an elastic layer over a rigid foundation, or a multilayered soil, excited by an uniform harmonic surface load moving with constant velocity. The displacements are obtained in a wave number domain after a double Fourier transform for the equations of motion. Actual displacements are then calculated using a FFT algorithm. Numerical results can be presented in the wave number and actual domains, showing the existence of different regimes (sub-Rayleigh and superRayleigh) depending on the load speed. Besides, for multilayered soils, we have to construct a global stiffness matrix using the same assembly process as in finite element analysis.
\end{abstract}


A more complete study needs to take into account the railway track. In this case, a railway track model lying on a layered ground and submitted to a moving train can be developed and the resolution method uses the formalism of Fourier transform for a semi-analytical resolution in the wave number domain. It includes all elements of the track (rails, pads, sleepers and ballast) and allows a parametric analysis of its different elements and evaluation of vertical displacements according to the speed, the weight and the composition of the trains. The handwriting of the stiffness matrix for a layered ground with the help of a fitted phase angle of Helmotz functions provides a fast numerical approach of the problem. Then Mach cones for the super-Rayleigh regime can be obtained near the track involving very high displacements on waves front. In the continuation of these numerical results, in situ measurements can be performed with a view to the validation of the model. These studies allow the construction of an available data basis for a possible development of models.

\section{INTRODUCTION}

The motivation for this presentation is to develop analytical, semi-analytical and numerical approaches to solve problems, involving ground vibrations due to moving loads in order to understand phenomena of wave propagation induced by rail and road traffic. In fact, during the last thirty years, damage due to ground vibrations caused by rail and road traffic has increased considerably, leading to environmental consequences (vibrations, noise, discomfort and environmental deterioration ...). It is thus important to study these phenomena theoretically in order to envisage ways of reducing their impact on the built environment. This is particularly true with regard to rail and road traffic which is becoming heavier and faster. For example, in the North West of France, more particularly in the region of the Somme Bay where grounds are constituded mainly by peat and soft clay, observations have revealed the presence of important displacements at the soil surface near railway tracks [1]. Also noticed in Sweden for grounds constituted by soft clay [2], these displacements involve with upsetting amplitudes in the track during heavy and high speed train passages.

To remember briefly some previous studies, we can notice the two-dimensional problem of the steady-state motion of a static line load in an unbounded body which was first considered by Eason et al [3]. Eason [4] also studied the two-dimensional steady-state problem for an uniform half-space, using Fourier transform methods. Cole and Huth [5] considered the same problem for a constant normal line load and obtained analytical forms for the solutions of displacements, in the subsonic, transonic and supersonic cases, using Helmholtz decomposition. These various cases are defined as :

- subsonic if the load speed is lower than the shear wave speed $c_{2}$,

- transonic if the load speed is included between the shear wave speed and the compressive wave speed $\mathrm{c}_{1}$,

- supersonic if the load speed is higher than the compressive wave speed.

Also, sometimes it is interesting to appeal to an other classification, such as :

- sub-Rayleigh if the load speed is lower than the Rayleigh wave speed $\mathrm{c}_{\mathrm{R}}$,

- super-Rayleigh if the load speed is higher than the Rayleigh wave speed.

These typical speeds are defined as : 
- for the compressive wave : $c_{1}^{2}=\frac{\lambda+2 \mu}{\rho}$

- for the shear wave : $\mathrm{c}_{2}=\frac{\mu}{\rho}$

- for the Rayleigh wave (Viktorov formula) : $\frac{\mathrm{c}_{\mathrm{R}}}{\mathrm{c}_{2}} \cong \frac{0.87+1.12 \mathrm{v}}{1+\mathrm{v}}$

where $\lambda$ et $\mu$ are Lamé constants, $\rho$ is the density and $v$ is the Poisson's ratio.

Georgiadis and Barber [6] corrected the Cole and Huth solution for the transonic regime. Fryba [7] also investigated the possibility of shocks in the ground due to a line load moving at constant speed at or beyond the Rayleigh wave speed. The method is based on a coupling using a change of variables (linked to the moving load) and a triple Fourier transform. This approach was also used by other authors, for example : Niwa and Kobayashi [8], Alabi [9], Jones et al [10]. Similarly, Keer [11] extended the study of the subsonic case to a moving harmonic line load with some numerical solutions. More recently, Gunaratne and Sanders [12] also studied the response of a layered elastic medium to a moving strip using a layer stiffness approach and viscous damping. Also, Lefeuve-Mesgouez et al [13] have obtained numerical results for the vertical displacements in the case of a vertical harmonic strip load moving with speed beyond the Rayleigh wave speed of the ground. The transmission of vibrations over the surface of the ground, due a high-speed moving, vertical harmonic strip load, is also investigated by the same authors [15], in the case of a two-dimensional problem with the ground modelled as an elastic half-space. Numerical results for the displacements on the surface are obtained for loads moving with speeds up to and beyond the Rayleigh wave speed of the half-space. De Barros and Luco [14] investigated the response of a layered viscoelastic half-space to a moving constant line load, and studied the stresses and strains. The transient motion for a line load which is suddenly applied on the ground and then moves with constant speed has been studied by Payton [16].

Eason et al [3] also studied the three-dimensional problem of a point load moving in an unbounded solid. Eason [4] and Lansing [17] investigated the three-dimensional problem for an uniform half-space. Alabi [18], [19] represented a train by a set of vertical moving point loads, and also studied the case of an oblique load for speeds up to half the Rayleigh wave speed. The three dimensional problem of a point load moving at constant speed on the ground demonstrating the possibility of shock formation in the ground has been studied by a lot of authors, for example Fryba [7], De Barros and Luco [20], Krylov [21], ... . Ground vibration in the vicinity of a moving harmonic rectangular load on a half-space can be also deduced (Jones et al [10]). For the same loading, displacements can be found in the case of a multilayered soil or of an elastic layer over a rigid foundation (Lefeuve-Mesgouez et al [22]. For the same characteristics of ground, it is also possible to obtain the surface vibration due to a sequence of high speed moving harmonic rectangular loads (Lefeuve-Mesgouez et al [23]).

This brief presentation don't give a complete state of art about the general problem concerning with the ground response for moving loads. Nevertheless, this point of view brings useful informations allowing a correct approach for the next situations :

- two or three dimensional analysis;

- models of ground : half-space, elastic or viscoelastic layer over a rigid foundation, multilayered soil ;

- models of loadings : line load, strip load or rectangular load, sequence of loads. 
In the objective to present the more important conclusions deduced from these papers, in the next section we will investigate theoretically some problems for the ground vibration in the vicinity of a high-speed moving harmonic load.

\section{GROUND RESPONSE FOR HIGH-SPEED MOVING LOADS}

For this presentation, we consider only the case of a strip load (two-dimensional problem) and a rectangular load (three-dimensional problem) moving with a constant speed.

2.1. Two-dimensional problem - Case of a strip load

\subsubsection{Strip load moving on an elastic half-space}

The model considered is shown in Figure 1. The strip load has a width of $2 b$ and is aligned with respect to the $\mathrm{x}_{2}$-axis. It rests on an homogeneous, isotropic, half-space, with material properties E (Young's modulus), $\rho$ (density), $v$ (Poisson's ratio). We consider the soil exhibiting hysteretic damping (coefficient $\eta$ ) which yields complex body wave speeds as follows :

$$
\begin{aligned}
& \mathrm{c}_{1}^{2}=\frac{\lambda+2 \mu}{\rho}(1+\mathrm{i} \eta) \\
& \mathrm{c} 2_{2}=\frac{\mu}{\rho}(1+\mathrm{i} \eta)
\end{aligned}
$$

But for load speeds above the Rayleigh wave speed, yielding a quasi-causal solution, we need to modify the definition of the loss factor to :

$$
\begin{aligned}
\mathrm{c}_{1}^{2} & =\frac{\lambda+2 \mu}{\rho}[1+\mathrm{i \eta} \operatorname{sgn}(\omega-\beta \mathrm{c})] \\
\mathrm{c}_{2} & =\frac{\mu}{\rho}[1+\mathrm{i \eta} \operatorname{sgn}(\omega-\beta \mathrm{c})]
\end{aligned}
$$

where $\omega$ is the load pulsation, $c$ the load speed and $\beta$ the Fourier parameter relative to the moving space variable $x$.

An harmonic vertical load acts uniformly over the strip.

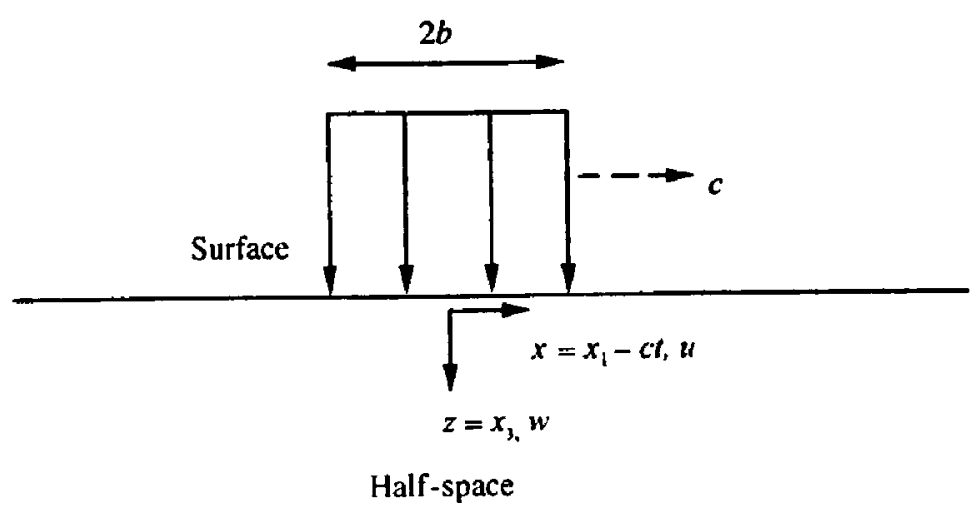

Fig. 1 - Geometry of model 
By introducing a Helmholtz decomposition in the Navier's elastodynamic equations and the stress-strain relatinship, we obtain the following wave equations for the two-dimensional model :

$$
\begin{aligned}
& \left(\frac{\partial^{2}}{\partial \mathrm{x}_{1}^{2}}-\frac{\partial^{2}}{\partial \mathrm{x}_{3}^{2}}\right) \Phi-\frac{1}{\mathrm{c}_{1}^{2}} \frac{\partial^{2} \Phi}{\partial \mathrm{t}^{2}}=0 \\
& \left(\frac{\partial^{2}}{\partial \mathrm{x}_{1}^{2}}-\frac{\partial^{2}}{\partial \mathrm{x}_{3}^{2}}\right) \Psi-\frac{1}{\mathrm{c}_{2}^{2}} \frac{\partial^{2} \Psi}{\partial \mathrm{t}^{2}}=0
\end{aligned}
$$

with :

$$
\mathrm{u}_{1}=\frac{\partial \Phi}{\partial \mathrm{x}_{1}}-\frac{\partial \Psi}{\partial \mathrm{x}_{3}}, \quad \mathrm{u}_{3}=\frac{\partial \Phi}{\partial \mathrm{x}_{3}}+\frac{\partial \Psi}{\partial \mathrm{x}_{1}}
$$

where $\Phi$ and $\Psi$ are the Helmholtz potentials, the co-ordinates $\left(\mathrm{x}_{1}, \mathrm{x}_{3}\right)$ are the fixed frame of reference, $u_{1}$ and $u_{3}$ are the horizontal and vertical displacements respectively. In terms of the scalar potentials, the boundary conditions for this problem are as follows :

$$
\begin{aligned}
& \text { - at } \mathrm{x}_{3}=0 \\
& \sigma_{33}=\lambda \frac{\partial^{2} \Phi}{\partial \mathrm{x}_{1}^{2}}+(\lambda+2 \mu) \frac{\partial^{2} \Phi}{\partial \mathrm{x}_{3}^{2}}+2 \mu \frac{\partial^{2} \Psi}{\partial \mathrm{x}_{1} \partial \mathrm{x}_{3}}=\left\{\begin{array}{l}
-\frac{\mathrm{p}}{2 \mathrm{~b}} \mathrm{e}^{\mathrm{i} \omega \mathrm{t}} \text { if }\left|\mathrm{x}_{1}-\mathrm{ct}\right|<\mathrm{b} \\
0
\end{array}\right. \\
& \sigma_{13}=\mu\left[2 \frac{\partial^{2} \Phi}{\partial \mathrm{x}_{1} \partial \mathrm{x}_{3}}+\frac{\partial^{2} \Psi}{\partial \mathrm{x}_{1}^{2}}+\frac{\partial^{2} \Psi}{\partial \mathrm{x}_{3}^{2}}\right]=0
\end{aligned}
$$

- at $x_{3}=\infty$, there are no reflections, which means that all wave motions are in the positive $\mathrm{x}_{3}$ - direction.

We introduce a frame of reference moving with the load (Eq. 13), in order to eliminate the time variable. We then define a Fourier transform on the space variable relative to the motion (Eq. 14) :

$$
\begin{aligned}
& x=x_{1}-\text { ct } \quad y=x_{2} \quad z=x_{3} \\
& \bar{h}(\beta, z)=\int_{-\infty}^{+\infty} h(x, z) e^{i \beta x} d x
\end{aligned}
$$

The Fourier transform is applied for Eqs (8), (9), (11) and (12). Taking into account that reflexions from $\mathrm{z}=\infty$ are disallowed, the Helmholtz potentials and then the longitudinal and vertical displacements can be obtained in the transform domain. The actual displacements in the $(\mathrm{x}, \mathrm{y})$ domain are deduced by means of the inverse Fourier transform. To perform this inverse Fourier transform, we use the well-known Fast Fourier Transform (F.F.T.) algorithm [24]. The displacements on the surface of the ground are then given by the following integral expressions : 
- for the longitudinal displacement :

$$
U=\left\{-\frac{i P}{2 \pi \mu b} \int_{-\infty}^{+\infty} \frac{\sin \beta b}{\overline{F(\beta)}}\left(\beta^{2}+\alpha_{2}^{2}-2 \alpha_{1} \alpha_{2}\right) e^{i \beta x} d \beta\right\} e^{i \omega t}
$$

- for the vertical displacement :

$$
W=\left\{-\frac{P}{2 \pi \mu} \int_{-\infty}^{+\infty} \frac{\sin \beta b}{\beta b} \frac{\alpha_{1}}{\overline{F(\beta)}} k_{2}^{2}\left(\frac{\beta}{k}-1\right)^{2} e^{i \beta x} d \beta\right\} e^{i \omega t}
$$

with

$$
\begin{aligned}
& \alpha_{\mathrm{i}}^{2}=\beta^{2}-\mathrm{k}_{\mathrm{i}}^{2}\left(1-\frac{\beta}{\mathrm{k}}\right)^{2}, \mathrm{i}=1,2 \\
& \mathrm{k}=\frac{\omega}{\mathrm{c}}, \quad \mathrm{k}_{\mathrm{i}}=\frac{\omega}{\mathrm{c}_{\mathrm{i}}} \\
& \overline{\mathrm{F}(\beta, \gamma)}=\left(\alpha_{2}^{2}+\beta^{2}\right)^{2}-4 \alpha_{1} \alpha_{2} \beta^{2}
\end{aligned}
$$

We note that if $\mathrm{c}=0 \mathrm{~m} / \mathrm{s}$, Eqs (15) and (16) reduce to the known expressions for a stationary harmonic vibrating strip load given for example by Le Houédec [25], and equation (19) reduces to the well known Rayleigh function; thus $\overline{\mathrm{F}}$ is the Rayleigh function adapted to a moving load.

For the numerical results, the data concerning with the soil characteristics are given in Table 1. Particularly, the soil A is chosen from a British Rail site at which the constants have been measured. For this soil, the values of the Rayleigh, shear and compression wave speeds are $\mathrm{c}_{\mathrm{R}}=242 \mathrm{~m} / \mathrm{s}, \mathrm{c}_{2}=263 \mathrm{~m} / \mathrm{s}$ and $459 \mathrm{~m} / \mathrm{s}$ respectively. The next results describe the behaviour of the vertical response for different load speeds.

\begin{tabular}{|l|c|c|c|c|}
\hline & Soil A & Soil B & Soil C & Soil D \\
\hline $\mathrm{E}(\mathrm{Pa})$ & $2.69 \times 10^{8}$ & $5.38 \times 10^{8}$ & $10.76 \times 10^{8}$ & $2.0 \times 10^{8}$ \\
$\rho\left(\mathrm{kg} \cdot \mathrm{m}^{-3}\right)$ & 1550 & 3100 & 2000 & 1250 \\
$\nu$ & 0.257 & 0.257 & 0.257 & 0.257 \\
$\eta$ & 0.1 & 0.1 & 0.1 & 0.1 \\
$c_{R}(\mathrm{~m} / \mathrm{s})$ & 242 & 242 & 426 & 232 \\
$c_{2}(\mathrm{~m} / \mathrm{s})$ & 263 & 263 & 463 & 252 \\
$c_{1}(\mathrm{~m} / \mathrm{s})$ & 459 & 459 & 809 & 441 \\
\hline
\end{tabular}

Table 1 - Material properties

Concerning with the soil A, five different frequencies are chosen for the moving load : $8 \mathrm{~Hz}, 16 \mathrm{~Hz}, 32 \mathrm{~Hz}, 48 \mathrm{~Hz}$ and $64 \mathrm{~Hz}$ respectively. For the first results showing the effect of load speed on the vertical motion of half-space, this one is non-dimensionalized by strip length. 
Figs 2, 3 and 4 give the results for $\mathrm{c}=0 \mathrm{~m} / \mathrm{s}$ (stationary load), $\mathrm{c}=200 \mathrm{~m} / \mathrm{s}$ (subsonic case) and $\mathrm{c}=400 \mathrm{~m} / \mathrm{s}$ (transonic and super-Rayleigh case).

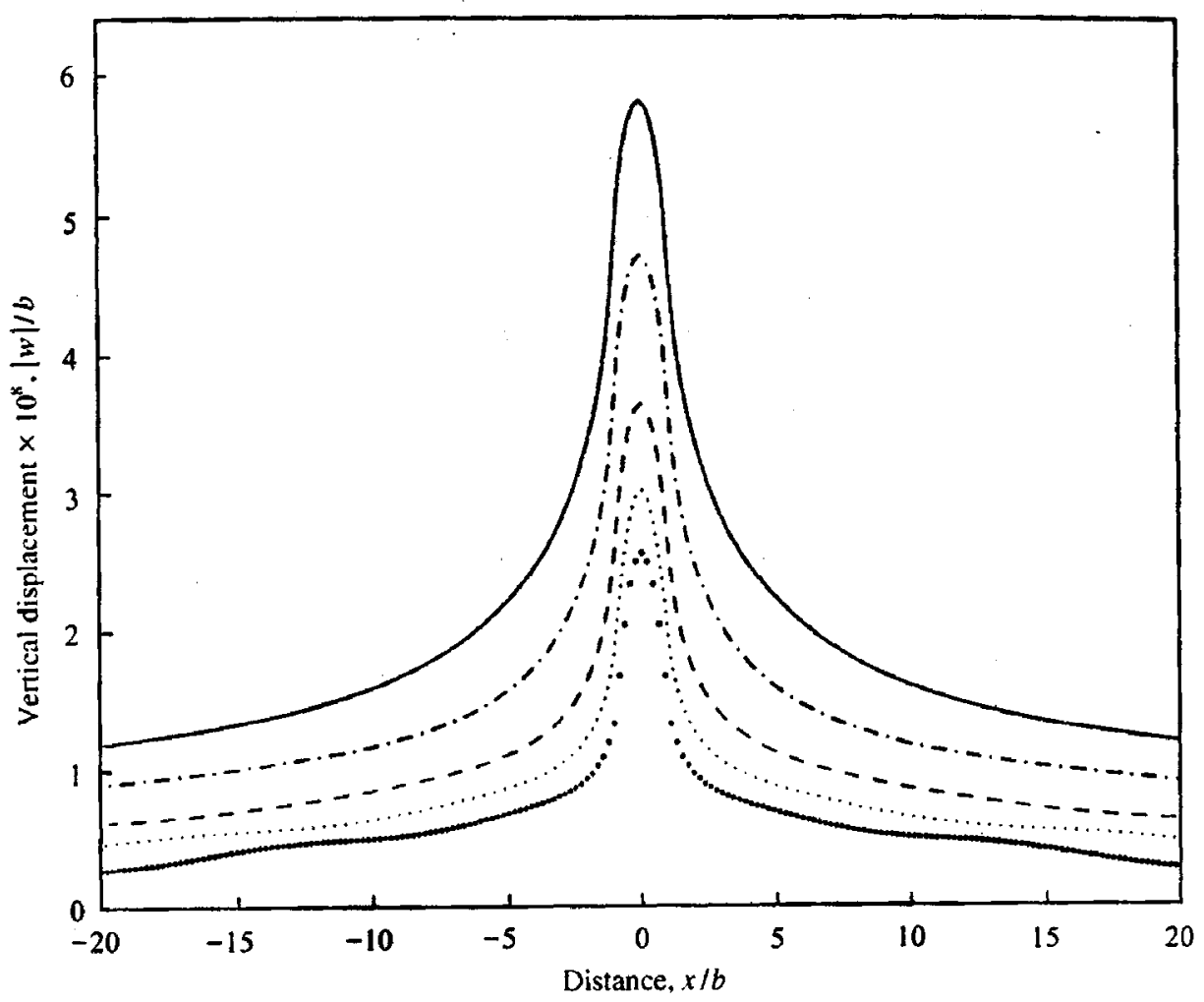

Fig. 2 - Non-dimensional vertical motion for $\mathrm{c}=0 \mathrm{~m} / \mathrm{s}$ : solid line $\mathrm{f}=8 \mathrm{~Hz}$, dash $-\operatorname{dot} \mathrm{f}=16 \mathrm{~Hz}$, dashed $\mathrm{f}=32 \mathrm{~Hz}$, light-dot $\mathrm{f}=48 \mathrm{~Hz}$, heavy $-\operatorname{dot} \mathrm{f}=64 \mathrm{~Hz}$.

In Fig. 2, the curves are perfectly symmetric and we note that the amplitude of the vertical displacement increases as the excitation frequency decreases.

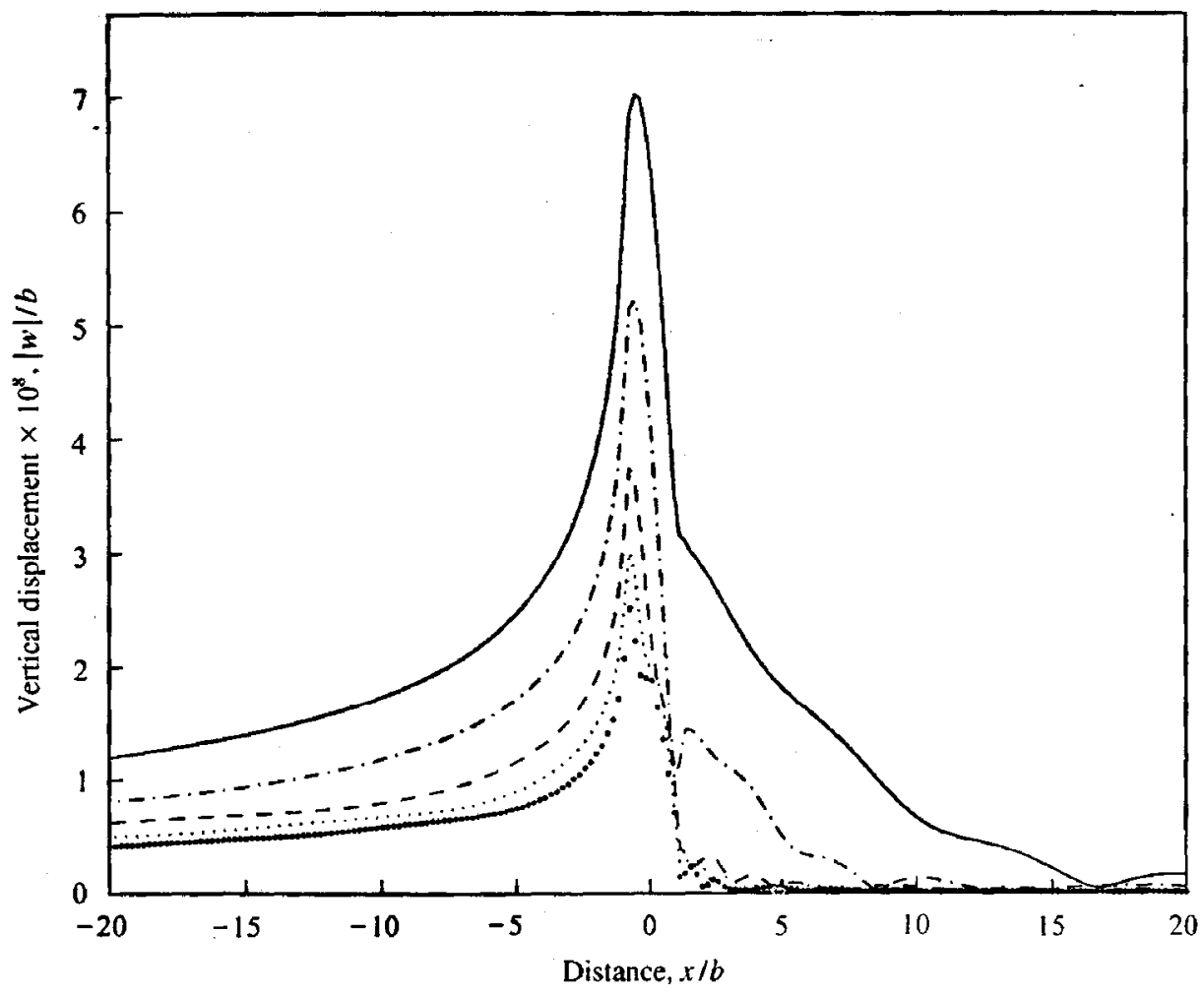

Fig. 3 - Non-dimensional vertical motion for $\mathrm{c}=200 \mathrm{~m} / \mathrm{s}$ : solid line $\mathrm{f}=8 \mathrm{~Hz}$, 
dash $-\operatorname{dot} f=16 \mathrm{~Hz}$, dashed $\mathrm{f}=32 \mathrm{~Hz}$, light-dot $\mathrm{f}=48 \mathrm{~Hz}$, heavy $-\operatorname{dot} \mathrm{f}=64 \mathrm{~Hz}$.

In Fig. 3, except for the frequency $8 \mathrm{~Hz}$, the responses are clearly modified and represent a wavefront with almost no displacement in front of the load, since the load speed is beyond the Rayleigh wave speed.

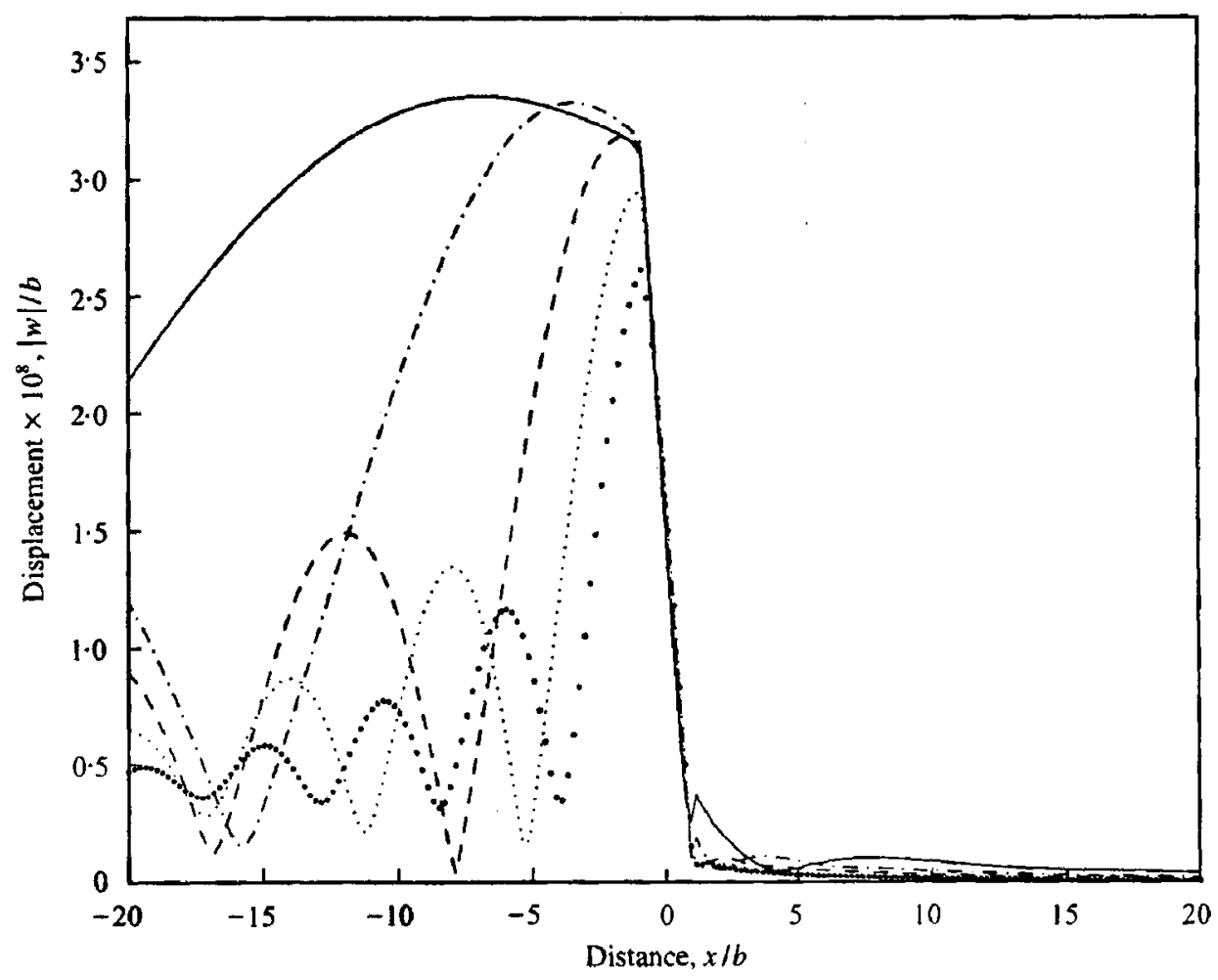

Fig. 4 - Non-dimensional vertical motion for $\mathrm{c}=400 \mathrm{~m} / \mathrm{s}$ : solid line $\mathrm{f}=8 \mathrm{~Hz}$, dash $-\operatorname{dot} \mathrm{f}=16 \mathrm{~Hz}$, dashed $\mathrm{f}=32 \mathrm{~Hz}$, light-dot $\mathrm{f}=48 \mathrm{~Hz}$, heavy $-\operatorname{dot} \mathrm{f}=64 \mathrm{~Hz}$.

In Fig. 4, all curves are fully modified, particularly behind the load. In front of the load, the responses vanish practically. Besides, increasing the load speed further (for example $\mathrm{c}=500$ $\mathrm{m} / \mathrm{s}$ ), we can observe that the maximum displacement is almost equivalent for all frequencies. Fig. 4 shows also the appearance of oscillations behind the load and the apparent wavelength of these oscillations depends on both frequency and speed of the load. The following parametric study investigates the factors which describe this phenomenon. For this, we define the Mach number $M_{R}$ as the ratio between the load speed and the Rayleigh wave speed :

$$
\mathrm{M}_{\mathrm{R}}=\frac{\mathrm{c}}{\mathrm{c}_{\mathrm{R}}}
$$

With the data given in Table 1 and for a frequency equal to $64 \mathrm{~Hz}$, Fig. 5 shows that the maximum amplitude, non-dimensionalized against appropriate Rayleigh wavelength $\lambda_{R}$, varies with different soil parameters. However, the apparent "wavelength » of oscillation is the same for all soil types, which will only be true for displacements over a half-space due to the dominant nature of the Rayleigh wave, Ewing et al [26]. 


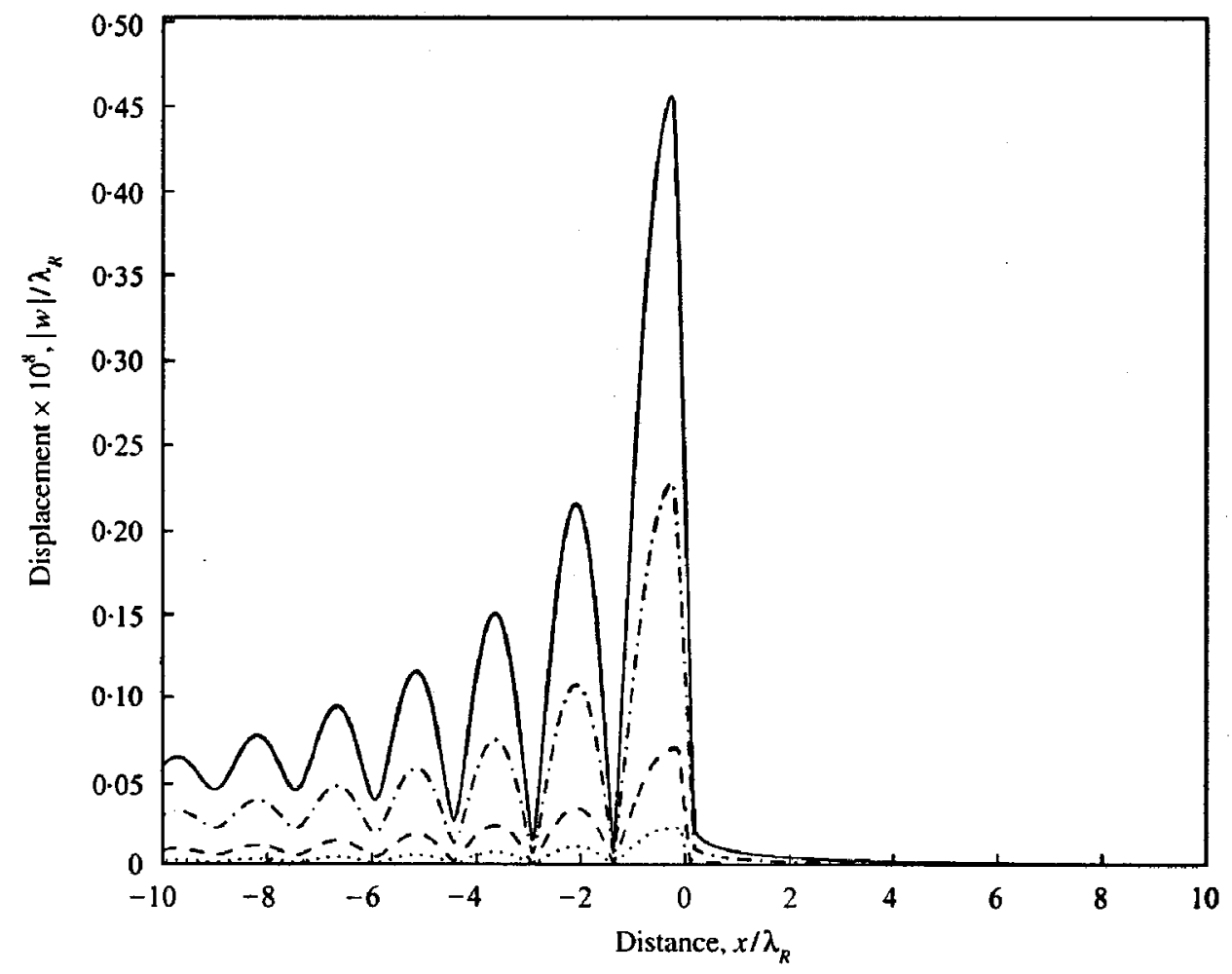

Fig. 5 - Non-dimensional vertical motion for four soil material parameters at load speed $\mathrm{c}=2 \mathrm{c}_{\mathrm{R}}$ : solid line soil A, dash-dot soil B, dashed soil C, light-dot soil D.

In Fig. 6, for high Mach numbers, $M_{R}>1$, the non-dimensional vertical displacements are plotted against $\frac{\mathrm{x}}{\lambda_{\mathrm{R}}\left(\mathrm{M}_{\mathrm{R}}^{2}-1\right)}$; which shows that the "wavelength» of the vibrations of displacements behind the load is directly proportional to this factor similar to results obtained in acoustics, Morse and Ingard [27].

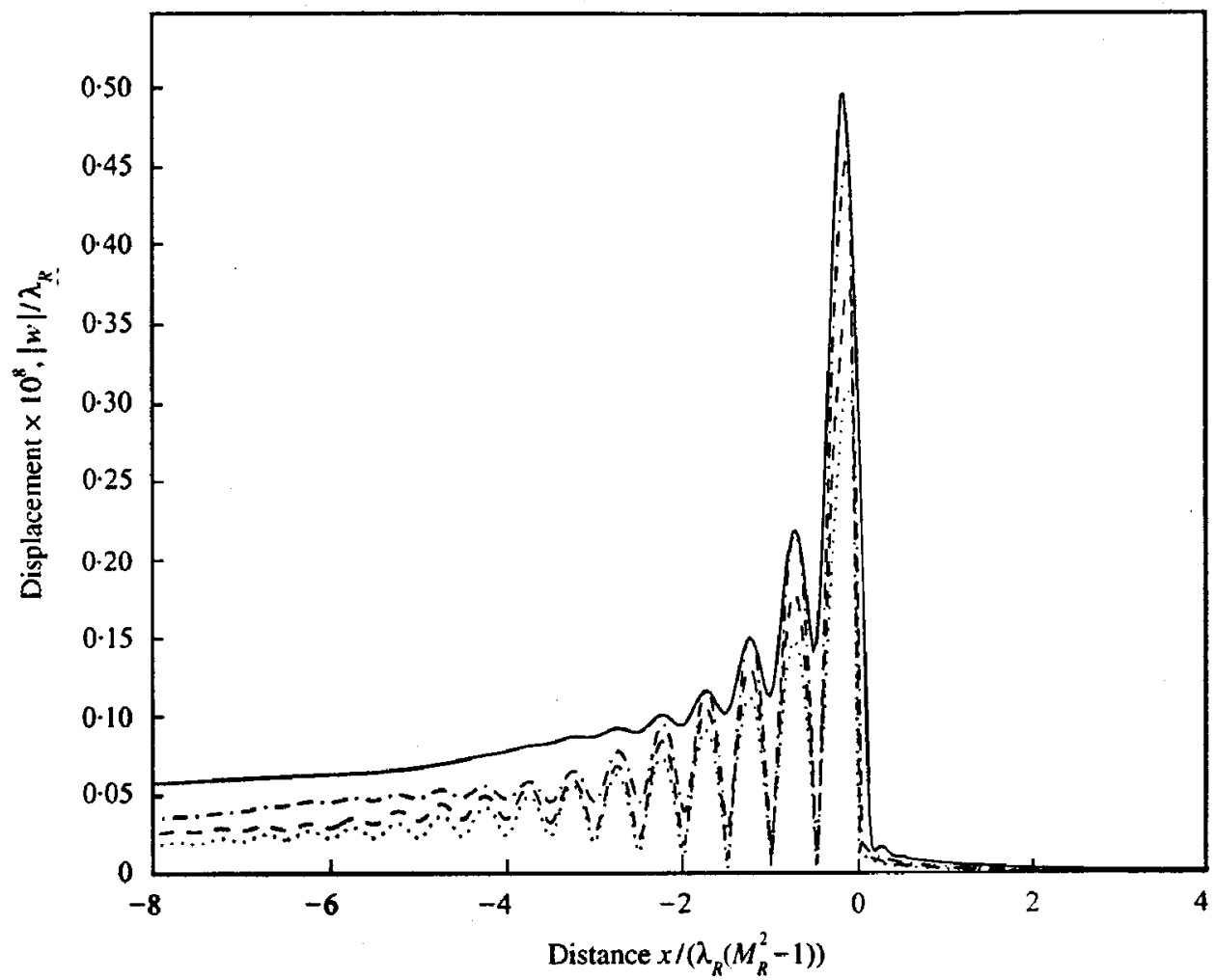

Fig. 6 - Non-dimensional vertical motion at frequency $\mathrm{f}=64 \mathrm{~Hz}$ for four load speeds : 
solid line $\mathrm{c}=\frac{3 \mathrm{c}_{\mathrm{R}}}{2} \quad$, dash-dot $\mathrm{c}=2 \mathrm{c}_{\mathrm{R}}$, dashed $\mathrm{c}=\frac{5 \mathrm{c}_{\mathrm{R}}}{2}$, light-dot $\mathrm{c}=3 \mathrm{c}_{\mathrm{R}}$.

The only material parameter which affects the apparent "oscillation» of the resultant wave is the Mach number $M_{R}$. Thus, if we denote by $\lambda^{*}$ the "period» of non-dimensional oscillations and by $\hat{\lambda}$ the wavelength of the actual vertical displacements, we observe :

$$
\lambda * \frac{\hat{\lambda}}{\lambda_{\mathrm{R}}}=\frac{1}{2}\left(\mathrm{M}_{\mathrm{R}}^{2}-1\right), \text { and hence } \hat{\lambda}=\frac{\pi\left(\mathrm{c}^{2}-\mathrm{c}_{\mathrm{R}}^{2}\right)}{\omega \mathrm{c}_{\mathrm{R}}}=\frac{2 \pi}{\beta_{2}-\beta_{1}}
$$

with

$$
\beta_{1}=\frac{\omega}{c+c_{R}} \quad \text { and } \quad \beta_{2}=\frac{\omega}{c+c_{R}}
$$

So, it is seen that the wavelength of the resultant wave is a combination of the two Rayleigh wavelengths. Finally, the wavelength of displacements, $\hat{\lambda}$, depends on three factors : the Rayleigh wave speed $c_{R}$, the load speed $c$ and its frequency $\omega ; \lambda^{*}$ depends on one factor, the Mach number $M_{R}$. This justifies the interest of the factor $\frac{1}{\lambda_{R}\left(M_{R}^{2}-1\right)}$ in the supersonic region.

\subsubsection{Strip load moving on an elastic layer overlaying a rigid foundation}

Now, an other model is considered : the strip load rests on an homogeneous, isotropic, viscoelastic layer, with material properties E (Young's modulus), $\rho$ (density), v (Poisson's ratio) and «modified» hysteretic damping as presented earlier; this layer is overlaying a rigid foundation. The two-dimensional model is presented in Fig. 7.

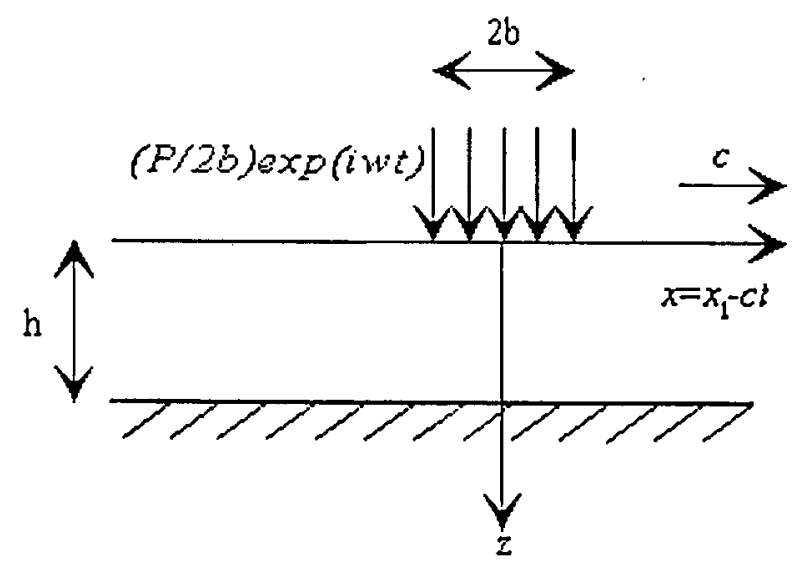

Fig. 7 - Geometry of the two-dimensional model.

In this case, the transformed potentials are written as follows :

$$
\begin{aligned}
& \bar{\Phi}=\overline{\mathrm{A}(\beta)} \mathrm{e}^{-\alpha_{1} \mathrm{z}}+\overline{\mathrm{C}(\beta)} \mathrm{e}^{\alpha_{1} \mathrm{z}} \\
& \bar{\Psi}=\overline{\mathrm{B}(\beta)} \mathrm{e}^{-\alpha_{2} \mathrm{z}}+\overline{\mathrm{D}(\beta)} \mathrm{e}^{\alpha_{2} \mathrm{z}}
\end{aligned}
$$

where the functions $\overline{\mathrm{A}(\beta)}, \overline{\mathrm{B}(\beta)}, \overline{\mathrm{C}(\beta)}$ and $\overline{\mathrm{D}(\beta)}$ are determined taking into account the new boundary conditions : 
- at the surface of ground, we obtain the same conditions as previously,

- the displacements are equal to zero at the interface with the rigid foundation.

Combining the dynamic stiffness matrix analysis with the earlier approach (change of variable and Fourier transform), we obtain the following system :

$$
[\mathrm{T}]\{\overline{\mathrm{u}}\}=\{\bar{\tau}\}
$$

with $\quad\{\overline{\mathrm{u}}\}=\{\mathrm{i} \overline{\mathrm{w}}(0), \overline{\mathrm{u}}(0), \mathrm{i} \overline{\mathrm{w}}(\mathrm{h}), \overline{\mathrm{u}}(\mathrm{h})\}^{\mathrm{t}}$

and $\quad\{\bar{\tau}\}=\left\{-\mathrm{i} \overline{\sigma_{\mathrm{zz}}}(0),-\overline{\sigma_{\mathrm{zx}}}(0), \overline{\mathrm{i}} \overline{\mathrm{zz}}(\mathrm{h}), \overline{\sigma_{\mathrm{zx}}}(\mathrm{h})\right\}^{\mathrm{t}}$

and [T] is the symmetric $4 \times 4$ stiffness matrix whose terms are depending on $\lambda$ and $\mu$ (Lamé constants), $\beta, \alpha_{\mathrm{i}}$ (Eq. 17), $\mathrm{k}$ and $\mathrm{k}_{\mathrm{i}}$ (Eq. 18) and $\mathrm{h}$ (layer depth). Because of computational difficulties due to the exponential terms in the matrix [T], it is necessary to divide the layer into several sub-layers. Morever, these sub-layers can have different material properties adapting for each sub-layer the matrix [T], and then assembling all the different matrices as in finite element analysis. The simplest case is of just two sub-layers with $2 d=h$ :

$$
\left[\begin{array}{cccccc}
\times & \times & \times & \times & 0 & 0 \\
\times & \times & \times & \times & 0 & 0 \\
\times & \times & \times & \times & \times & \times \\
\times & \times & \times & \times & \times & \times \\
0 & 0 & \times & \times & \times & \times \\
0 & 0 & \times & \times & \times & \times
\end{array}\right]\left\{\begin{array}{c}
\mathrm{i} \overline{\mathrm{w}}(0) \\
\overline{\mathrm{u}}(0) \\
\mathrm{i} \overline{\mathrm{w}}(\mathrm{d}) \\
\overline{\mathrm{u}}(\mathrm{d}) \\
0 \\
0
\end{array}\right\}=\left\{\begin{array}{c}
-\mathrm{i} \overline{\sigma_{\mathrm{zz}}}(0) \\
-\mathrm{i} \overline{\sigma_{\mathrm{zx}}}(0) \\
0 \\
0 \\
\overline{\mathrm{i} \overline{\mathrm{zz}}}(2 \mathrm{~d}) \\
\overline{\sigma_{\mathrm{zx}}}(2 \mathrm{~d})
\end{array}\right\}
$$

For $\mathrm{c}=0 \mathrm{~m} / \mathrm{s}$, equation (28) reduces to the expressions given by Jones and Petyt [28] for a stationary vibrating strip load.

The influence of the layer's depth was studied by several authors, for example Waas [29] or Laghrouche [30]. For $M_{R}=0$ and for vertical vibrations, the critical depths are given by :

$$
\mathrm{h}_{\mathrm{i}, \mathrm{n}}=(2 \mathrm{n}-1) \frac{\mathrm{c}_{\mathrm{i}}}{4 \mathrm{f}}, \mathrm{n}=1,2,3 \ldots
$$

where $\mathrm{i}=1,2$ or $\mathrm{R}$ according to the wave type, and $\mathrm{f}$ is the load frequency. We can nondimensionalize the results by noting $h^{*}=\frac{h}{\lambda_{R}}$, and in this case, $h_{i, n}^{*}$ is depending on only (Poisson's ratio). For the soil A, the first adimensional critical depth is obtained for $\mathrm{h}_{1}^{*}=0.474$, very closed to 0.5 . This result is verified in Fig. 8 where we notice that the vertical displacements are really higher for $\mathrm{h}^{*}=0.5$, than for other values of $\mathrm{h}^{*}$. 

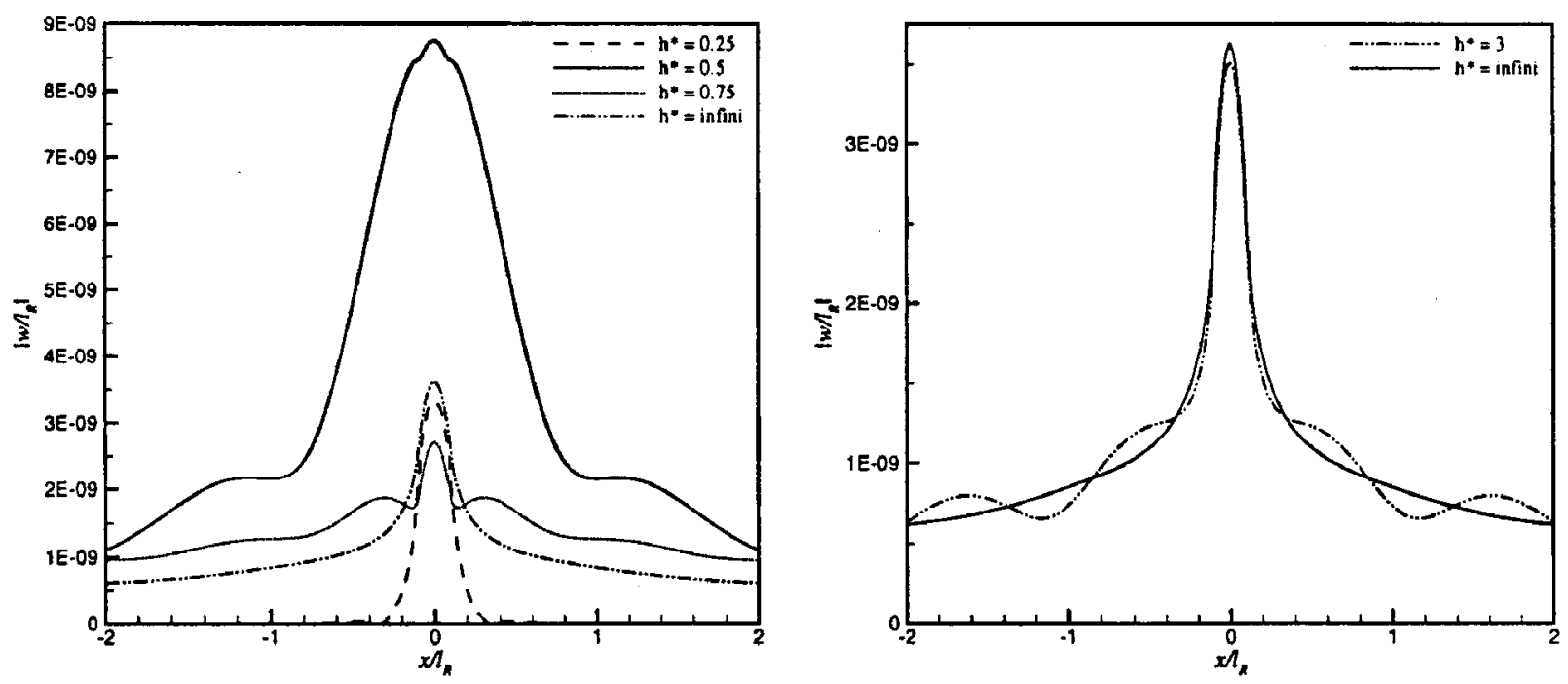

Fig. 8 - Critical depth of the elastic layer $\left(\mathrm{M}_{\mathrm{R}}=0\right)$.

When the load speed increases, the responses of the soil surface are modified, as shown in Fig. 9. For the sub-Rayleigh case $\left(\mathrm{M}_{\mathrm{R}}=0.5<1\right)$, the higher displacement is always obtained for $\mathrm{h}^{*}=0.5$ behind the load, but now the curves are not any more symmetric and in front of the load conclusions are not distinct. For the super-Rayleigh case $\left(\mathrm{M}_{R}=2>1\right)$, in front of the load displacements are practically cancelled, and behind the load we notice the classical oscillations with on average a more important amplitude for $\mathrm{h}^{*}=0.5$.

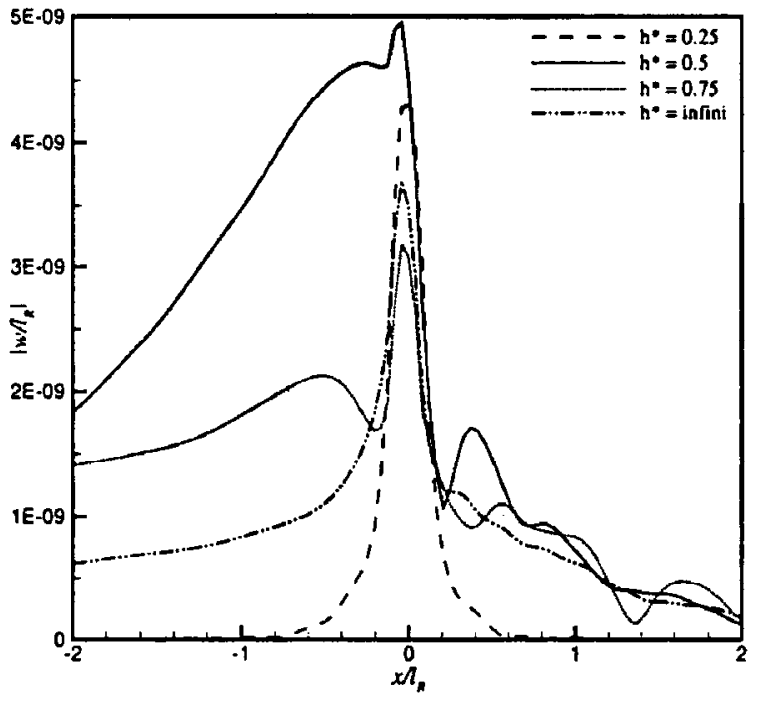

(a) $M_{R}=0.5$

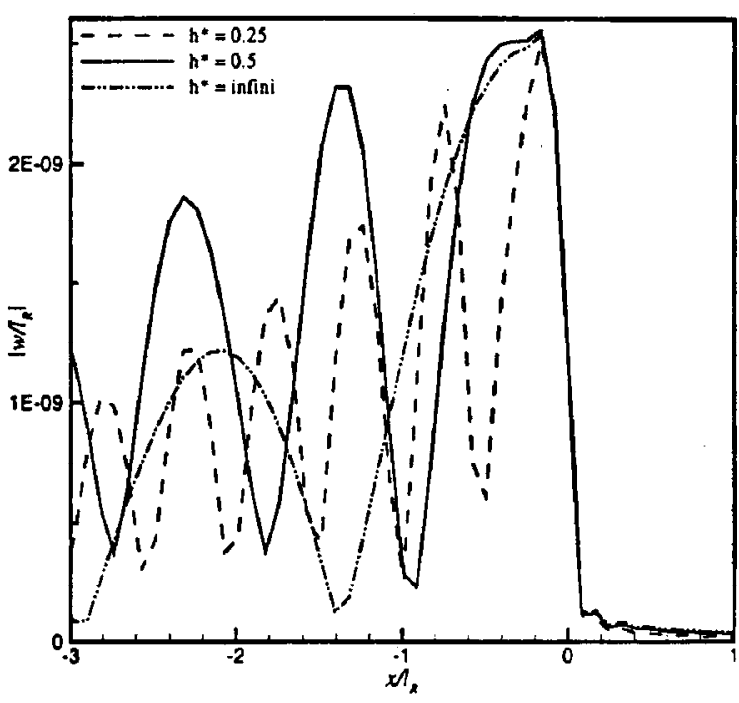

(b) $M_{R}=2$

Fig. 9 - Critical depth of the elastic layer $\left(\mathrm{M}_{R} \neq 0\right)$.

For $\mathrm{h}^{*}=0.5$, Fig. 10 shows a comparison of the vertical surface displacements for three values of $M_{R}: M_{R}=0$ (stationary case), $M_{R}=0.5$ (sub-Rayleigh case) and $M_{R}=2$ (superRayleigh case). For the stationary case, we obtain more important adimensional displacements that for moving loads : $8.8 \times 10^{-9}$ for $\mathrm{M}=0,5.0 \times 10^{-9}$ for $\mathrm{M}_{\mathrm{R}}=0.5$ and $2.5 \times 10^{-9}$ for $\mathrm{M}_{\mathrm{R}}=2$. These values are obtained directly under the load, but beyond some wavelengths behind the load, we notice on the contrary opposite conclusions. 


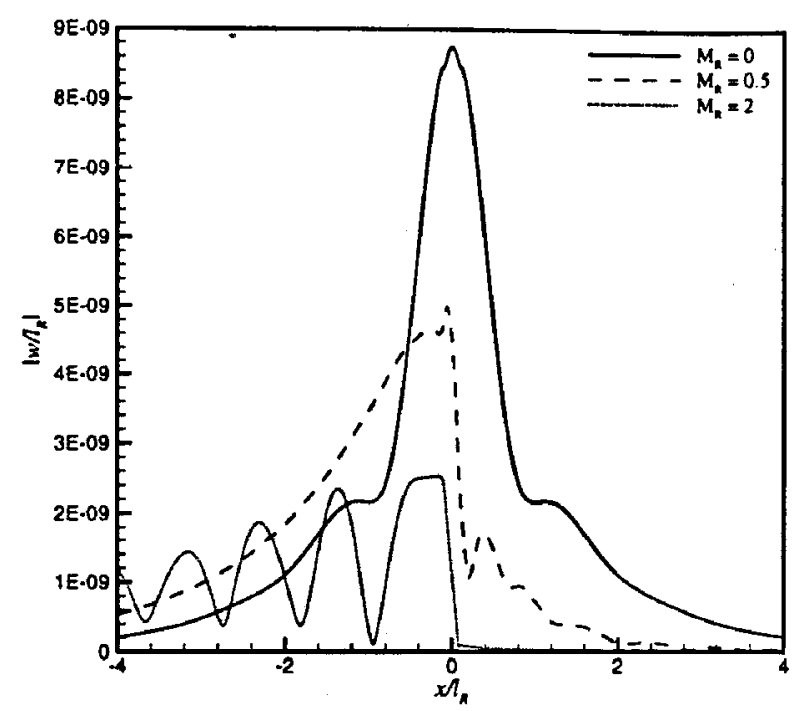

Fig. 10 - Comparison of displacements for various values of $\mathrm{M}_{\mathrm{R}}$.

2.1.3 - Strip load moving on an elastic layer overlaying a half-space

For this study, we use the two-dimensional model presented in Fig. 11.

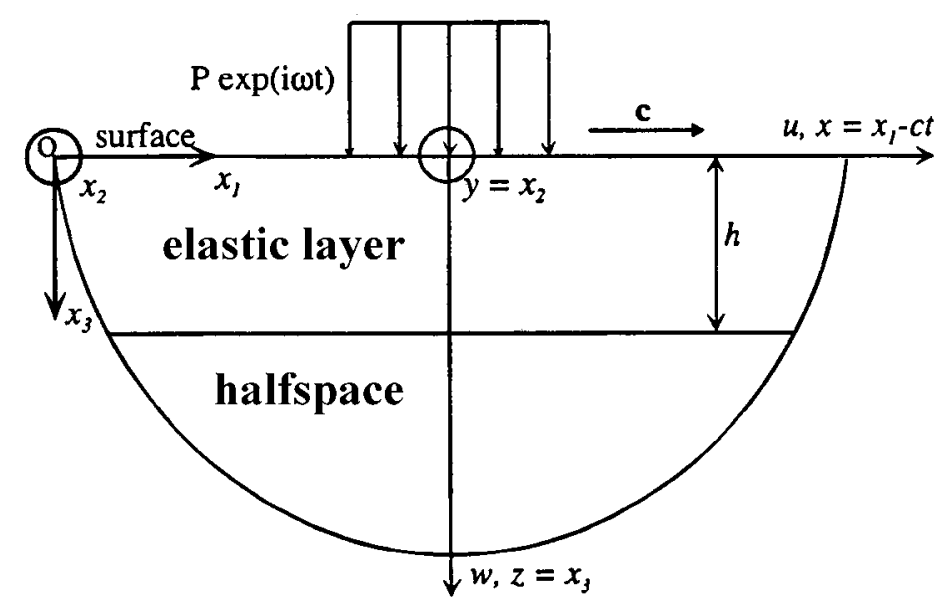

Fig. $11-2 \mathrm{D}$ model for an elastic layer overlaying a half-space.

In this case, equations are deduced taking into account the two previous approaches. First, we use a similar matrix system, as given in (28), where displacements at the interface with the half-space are now unknown :

$$
\left[\begin{array}{cccccc}
\times & \times & \times & \times & 0 & 0 \\
\times & \times & \times & \times & 0 & 0 \\
\times & \times & \times & \times & \times & \times \\
\times & \times & \times & \times & \times & \times \\
0 & 0 & \times & \times & \times & \times \\
0 & 0 & \times & \times & \times & \times
\end{array}\right]\left\{\begin{array}{c}
\mathrm{i} \overline{\mathrm{w}}(0) \\
\overline{\mathrm{u}}(0) \\
\mathrm{i} \overline{\mathrm{w}}(\mathrm{d}) \\
\overline{\mathrm{u}}(\mathrm{d}) \\
\mathrm{i} \overline{\mathrm{w}}(2 \mathrm{~d}) \\
\overline{\mathrm{u}}(2 \mathrm{~d})
\end{array}\right\}=\left\{\begin{array}{c}
-\overline{\mathrm{i} \sigma \overline{\mathrm{zz}}}(0) \\
-\overline{\sigma_{\mathrm{zx}}}(0) \\
0 \\
0 \\
\overline{\mathrm{i}} \overline{\mathrm{\sigma zz}}(2 \mathrm{~d}) \\
\overline{\sigma_{\mathrm{zx}}}(2 \mathrm{~d})
\end{array}\right\}
$$


Besides, at the interface between the layer bottom and the half-space, we write the equality for stresses and for displacements. After the results obtained for a half-space, we can relate the displacements on the half-space surface according to the stresses, by means of a matrix equation :

$$
\left\{\begin{array}{c}
\overline{\mathrm{i}_{\mathrm{zz}}^{1}}(0) \\
\overline{\sigma_{\mathrm{zx}}^{1}}(0)
\end{array}\right\}=[\mathrm{R}]\left\{\begin{array}{c}
\overline{\mathrm{iw}}(0) \\
\overline{\mathrm{u}^{1}}(0)
\end{array}\right\}
$$

where $[R]$ is a $2 \times 2$ stiffness matrix whose terms are depending on same data as [T].

Briefly, to simplify Eq. (30) in the objective to obtain six equations with six unknowns, we perform the two next operations :

- $\quad$ first, we substract the matrix [R] from the last matrix group $2 \times 2$ of the global stiffness matrix [T], allowing to eliminate the two last terms of the stress vector ;

- secondly, we introduce the boundary conditions for the moving load.

For the numerical results, we consider the case of a soft layer overlaying a more rigid half-space (Table 2).

\begin{tabular}{|l|c|c|}
\cline { 2 - 3 } \multicolumn{1}{c|}{} & Soft layer & « Rigid » half-space \\
\hline Young's modulus $(\mathrm{MPa})$ & 269 & 1076 \\
\hline Density $\left(\mathrm{kg} . \mathrm{m}^{-3}\right)$ & 1550 & 2000 \\
\hline Poisson ratio & 0.257 & 0.257 \\
\hline Loss factor & 0.1 & 0.1 \\
\hline Compression wave speed $(\mathrm{m} / \mathrm{s})$ & 459 & 809 \\
\hline Shear wave speed $(\mathrm{m} / \mathrm{s})$ & 263 & 463 \\
\hline Rayleigh wave speed $(\mathrm{m} / \mathrm{s})$ & 242 & 426 \\
\hline
\end{tabular}

Table 2 - Characteristics of the layer and the half-space.

For these data, in Fig.12, we obtain similar results as for Figs 8 and 9, except in the case of $M_{R}=0.5$ where the maximum displacement is not obtained for $h^{*}=0.5$ but for $h^{*}=0.25$. So, for a moving load, the reference linked to the critical depth disappears, even for the subsonic regime. 


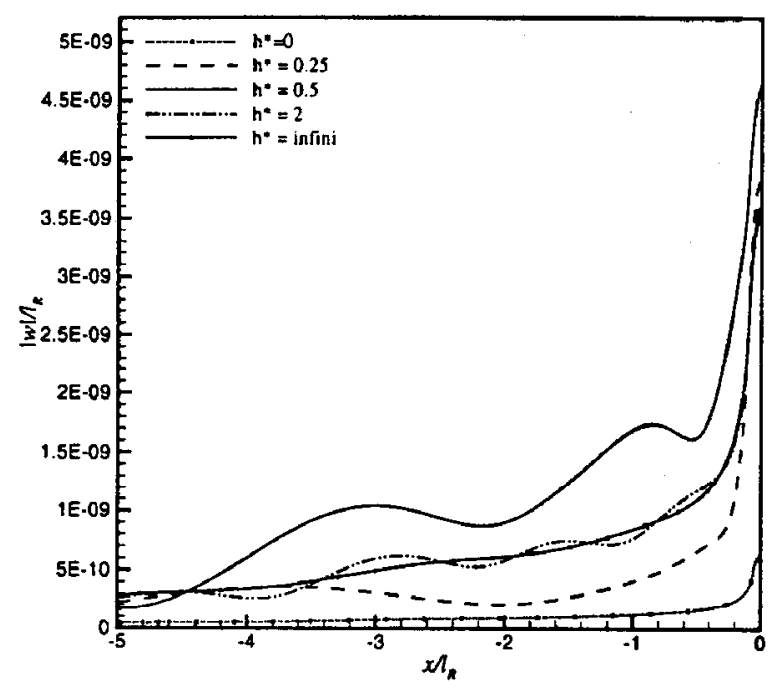

(a) $M_{R}=0$.

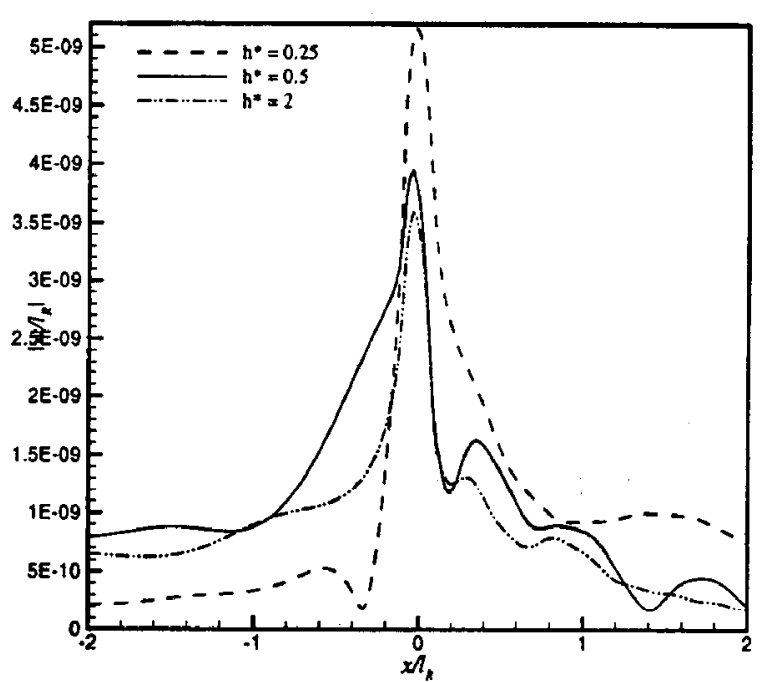

(b) $M_{R}=0.5$

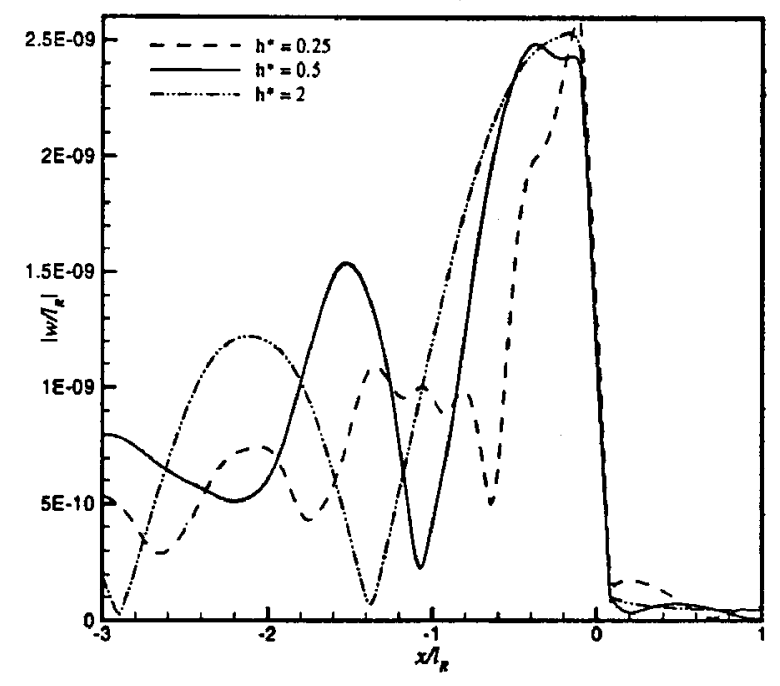

(c) $M_{R}=2$

Fig. 12 - Adimensional displacements for an elastic layer overlaying a half-space.

2.2. Three-dimensional problem - Case of a rectangular load

2.2.1. Rectangular load moving on an elastic half-space

The model considered is shown in Fig. 13.

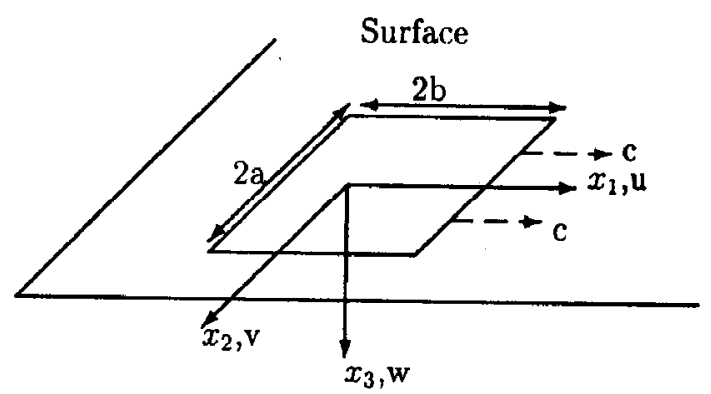

Fig. 13 - Geometry of the model. 
In this case, all data and assumptions written in the paragraph 2.1.1 are available. We only introduce :

- the dilatation $\Theta=\frac{\partial u_{1}}{\partial x_{1}}+\frac{\partial u_{2}}{\partial x_{2}}+\frac{\partial u_{3}}{\partial x_{3}}$

- the double Fourier transform on the space variables $\mathrm{x}$ and $\mathrm{y}$ :

$$
\overline{\mathrm{f}}(\beta, \gamma, z)=\frac{1}{2 \pi} \int_{-\infty}^{+\infty} \int_{-\infty}^{+\infty} \mathrm{f}(\mathrm{x}, \mathrm{y}, \mathrm{z}) \mathrm{e}^{-\mathrm{i}(\beta \mathrm{x}+\gamma \mathrm{y})} \mathrm{dx} d \mathrm{y}
$$

with the above definition, the changes of variables and functions and introducing :

$$
\alpha_{i}^{2}=\beta^{2}+\gamma^{2}-k_{i}^{2}\left(1-\frac{\beta c}{\omega}\right)^{2}, \quad i=1,2
$$

with $\mathrm{k}_{\mathrm{i}}=\frac{\omega}{\mathrm{c}_{\mathrm{i}}}$, we finally obtain :

$$
\left(\frac{\mathrm{d}^{2}}{\mathrm{dz}^{2}}-\alpha_{1}^{2}\right) \bar{\theta}=0
$$

Taking into account the condition to cancel the existence of waves propagating in the negative z-direction, the elastodynamic equation of half-space leads to the following system :

$$
\left(\frac{\mathrm{d}^{2}}{\mathrm{dz}^{2}}-\alpha_{2}^{2}\right)\left\{\begin{array}{c}
\overline{\mathrm{u}} \\
\overline{\mathrm{v}} \\
\overline{\mathrm{w}}
\end{array}\right\}=-\frac{\lambda+\mu}{\mu} \mathrm{Ae}^{-\alpha_{1} \mathrm{z}}\left\{\begin{array}{c}
\mathrm{i} \beta \\
\mathrm{i} \gamma \\
-\alpha_{1}
\end{array}\right\}
$$

The solution of Eq.(36) can be obtained by a combination of the solution of the homogeneous form of (36) and a particular integral in this equation :

$$
\left\{\begin{array}{c}
\bar{u} \\
\bar{v} \\
\bar{w}
\end{array}\right\}=\frac{A e^{-\alpha_{1} z}}{k_{1}^{2}\left(1-\frac{\beta c}{\omega}\right)^{2}}\left\{\begin{array}{c}
-i \beta \\
-i \gamma \\
\alpha_{1}
\end{array}\right\}+e^{-\alpha_{2} z}\left\{\begin{array}{l}
B \\
C \\
D
\end{array}\right\}
$$

If $\mathrm{P}$ is the total force acting on the rectangle and is uniformly distributed over it, the Fourier transform gives :

$$
\begin{aligned}
& \overline{\sigma_{\mathrm{zz}} \mathrm{z}=0}=-\frac{\mathrm{P}}{2 \pi \mathrm{ba}} \frac{\sin \beta \mathrm{b} \sin \gamma \mathrm{a}}{\beta \gamma} \\
& \overline{\sigma_{\mathrm{zx}} \mathrm{z}=0}=0
\end{aligned}
$$

Then, we can deduce expressions for A, B, C, D : 


$$
\begin{aligned}
& \mathrm{A}=\frac{\mathrm{k}_{1}^{2}}{\mu}\left(1-\frac{\beta \mathrm{c}}{\omega}\right)^{2} \frac{\alpha_{2}^{2}+\beta^{2}+\gamma^{2}}{\overline{\mathrm{F}}(\beta, \gamma)} \overline{\sigma_{\mathrm{zz}}=0} \\
& \mathrm{~B}=\frac{\mathrm{i}}{\mu} \frac{2 \alpha_{2} \alpha_{2} \beta}{\overline{\mathrm{F}(\beta, \gamma)}} \overline{\sigma_{\mathrm{zz}} \mathrm{z}=0}=\frac{\beta}{\gamma} \mathrm{C}
\end{aligned}
$$

and

$$
\mathrm{D}=\frac{\mathrm{i}}{\alpha_{2}}(\beta \mathrm{B}+\gamma \mathrm{C})
$$

with $\overline{\mathrm{F}(\beta, \gamma)}$ the Rayleigh function for a moving load in the 3D case :

$$
\overline{\mathrm{F}(\beta, \gamma)}=\left(\alpha_{2}^{2}+\beta^{2}+\gamma^{2}\right)^{2}-4 \alpha_{1} \alpha_{2}\left(\beta^{2}+\gamma^{2}\right)
$$

Transformed displacements are given by :

$$
\begin{aligned}
\left\{\begin{array}{c}
\overline{\mathrm{u}} \\
\overline{\mathrm{v}} \\
\overline{\mathrm{w}}
\end{array}\right\}= & \frac{\alpha_{2}^{2}+\beta^{2}+\gamma^{2}}{\overline{\mathrm{F}(\beta, \gamma)}} \frac{\overline{\sigma_{\mathrm{zz}}}}{\mu} \mathrm{e}^{-\alpha_{1} \mathrm{z}}\left\{\begin{array}{c}
-\mathrm{i} \beta \\
-\mathrm{i} \gamma \\
\alpha_{1}
\end{array}\right\} \\
& +\frac{2 \mathrm{i} \alpha_{1} \alpha 2}{\overline{\mathrm{F}(\beta, \gamma)}} \frac{\overline{\sigma_{\mathrm{zz}}}}{\mu} \mathrm{e}^{-\alpha_{2} \mathrm{z}}\left\{\begin{array}{c}
\beta \\
\mathrm{i}\left(\beta^{2}+\gamma^{2}\right) / \alpha_{2}
\end{array}\right\}
\end{aligned}
$$

At the surface of the ground, the vertical displacement is written as follows :

$$
\mathrm{w}(0)=\int_{-\infty}^{+\infty} \int_{-\infty}^{+\infty} \overline{\sigma_{\mathrm{zz}}} \frac{\alpha_{1} \mathrm{k}_{2}^{2}(1-\beta \mathrm{c} / \omega)^{2}}{2 \pi \mu \overline{\mathrm{F}(\beta, \gamma)}} \mathrm{e}^{\mathrm{i}(\beta \mathrm{x}+\gamma \mathrm{y})} \mathrm{d} \beta \mathrm{d} \gamma
$$

that is to say in the case of a rectangular load:

$$
w(0)=\frac{1}{4 \pi^{2}} \frac{P}{\mu} \int_{-\infty}^{+\infty} \int_{-\infty}^{+\infty} \frac{\sin \beta a}{\beta a} \frac{\sin \gamma b}{\gamma b} \frac{\alpha_{1} k_{2}^{2}(1-\beta c / \omega)^{2}}{\overline{F(\beta, \gamma)}} e^{i(\beta x+\gamma y)} d \beta d \gamma
$$

For a speed egal to zero, we can find results obtained by Jones and Petyt [31], and for a stationary harmonic load we obtain the same results as Thomson and Kobori [32].

For the numerical results, we use the characteristics data given for the soil A (Table 1). In the transform domain, for non-zero damping, the real part of the transformed displacements over the surface of the ground is plotted in Fig. 14, showing a sub-Rayleigh case and a superRayleigh case. According to the hypothesis, we obtain the visualisation of an ellipse or an hyperbola. The comparison between the theoretical equation of the conic and the numerical 
results shows a good agreement. In this figure, only the contribution of the Rayleigh wave can be seen because it is dominant at the surface.

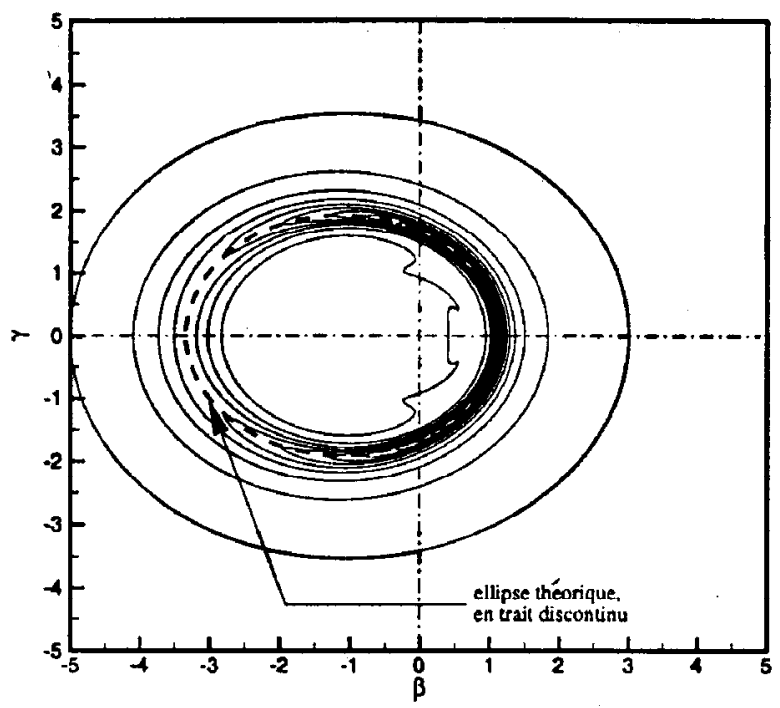

(a) $M_{R}=0.5$

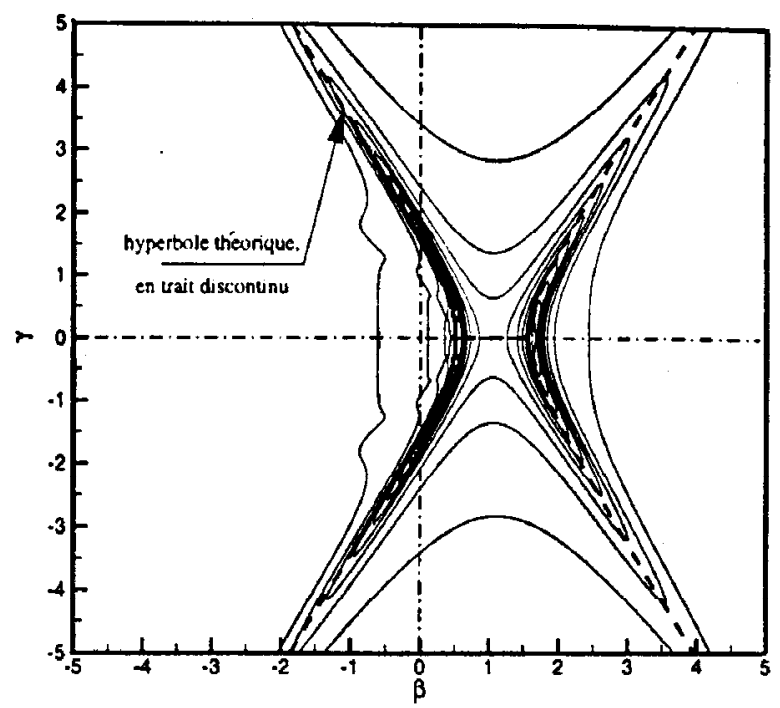

(b) $M_{R}=2$

Fig. 14 - Contour levels of the real part of the transformed vertical displacements for $\mathrm{M}_{R}=0.5$ and $\mathrm{M}_{\mathrm{R}}=2$.

To obtain the actual domain results, we use a F.F.T. with a grid of $2048 \times 2048$ points with a range of $-16<\beta, \gamma<16$ to avoid distorsion of the results. To analyse these ones, distances are non dimensionalised by Rayleigh wavelength $\lambda_{R}$ and Mach number relative to the Rayleigh wave $M_{R}$ is introduced. Fig. 15 presents the displacements along the line $y=0$ for different load speeds.

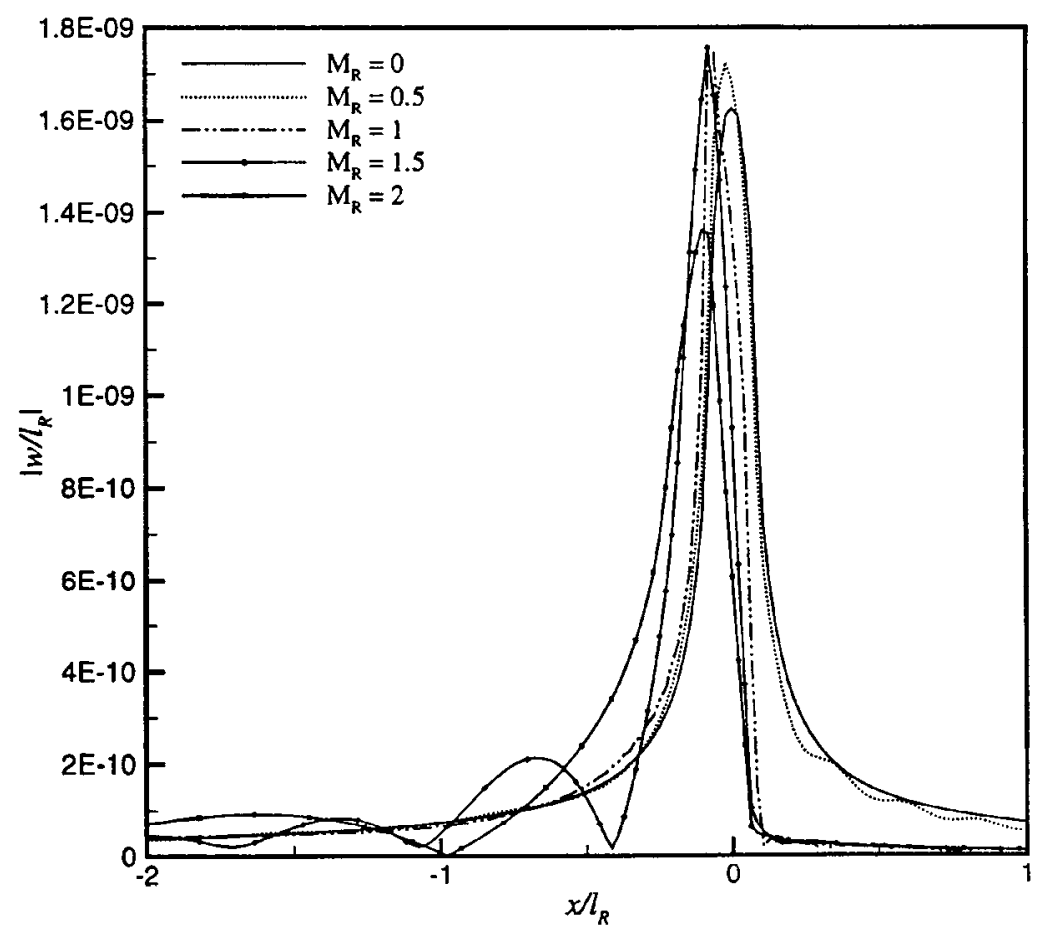

Fig. 15 - Amplitude of vertical displacements along the line $\mathrm{y}=0$ for different load speeds. 
When $\mathrm{M}_{\mathrm{R}}$ increases, the maximum of non dimensionalized displacements amplitude increases a little, from $1.63 \times 10^{-9}$ for $\mathrm{M}_{\mathrm{R}}=0$ to $1.74 \times 10^{-9}$ for $\mathrm{M}_{\mathrm{R}}=1$, but then it decreases continuously to $1.36 \times 10^{-9}$ for $M_{R}=2$. Morever, for low values of $M_{R}$, the maximum is situated at the middle of the rectangle, whereas for greater Mach numbers, the maximum moves to the back edge of the rectangle.

When $\mathrm{M}_{\mathrm{R}}$ is low, the distribution of displacements is focused around the load in the near field, whereas with increasing $M_{R}$, the distribution spreads behind the load and on the sides (Fig. 16). For $\mathrm{M}_{\mathrm{R}}>1$, the displacements are contained within the two Mach lines, and are almost equal to zero in front of the load due to a Rayleigh wave speed lower than the load speed.

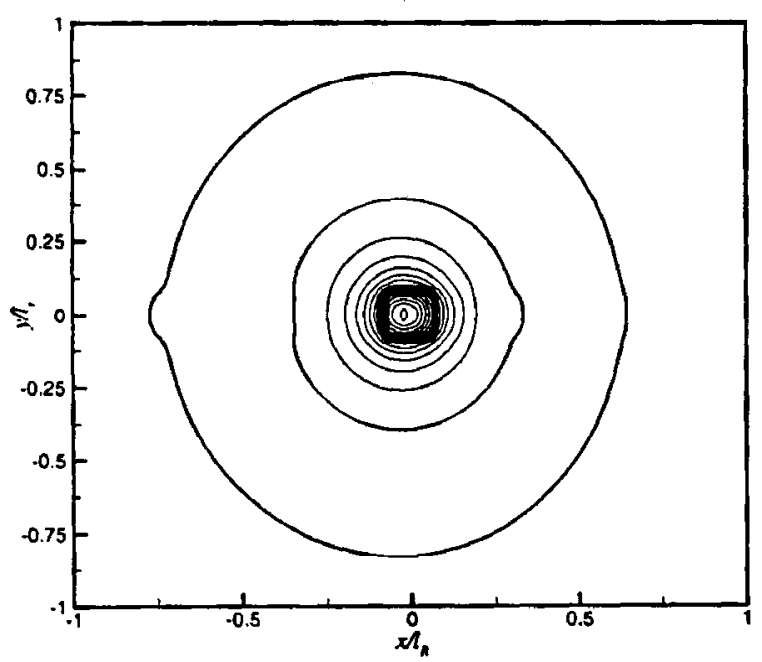

(a) $M_{R}=0.5$

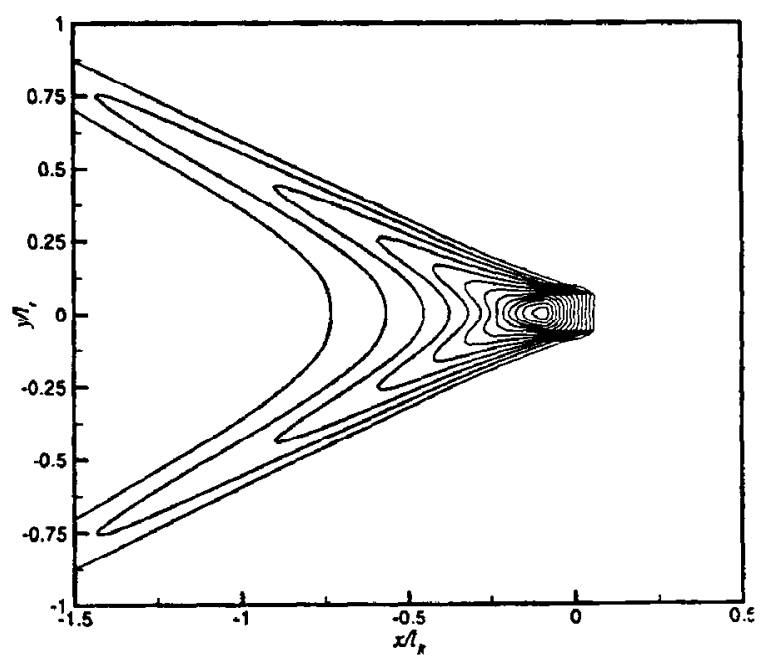

(b) $M_{R}=2$

Fig. 16 - Contour levels of the real part of vertical displacements for $M_{R}=0.5$ and $M_{R}=2$.

\subsubsection{Rectangular load moving on an elastic layer over a rigid foundation}

The ground is modelled as an elastic layer of depth $\mathrm{h}$ overlaying a rigid foundation.

Now, the boundary conditions are changed :

- for $z=0\left\{\begin{array}{l}\sigma_{z z}=-\frac{P}{4 a b} e^{i \omega t} \quad|x|<b,|y|<a \\ \sigma_{x z}=\sigma_{y z}=0\end{array}\right.$

- for $\mathrm{z}=\mathrm{h}: \mathrm{u}_{1}=\mathrm{u}_{2}=\mathrm{u}_{3}=0$

We use the same method to solve the problem i.e. changes of variables and functions, and double Fourier transform on the space variables $\mathrm{x}$ and $\mathrm{y}$. Now, waves can propagate in the negative z-direction due to reflections at the boundary with the bedrock, and the resolution of (36) gives in this case : 


$$
\begin{aligned}
\left\{\begin{array}{c}
\bar{u} \\
\bar{v} \\
\bar{w}
\end{array}\right\}=\frac{A e^{-\alpha_{1} z}}{k_{1}^{2}\left(1-\frac{\beta c}{\omega}\right)^{2}}\left\{\begin{array}{c}
-i \beta \\
-i \gamma \\
\alpha_{1}
\end{array}\right\}+e^{-\alpha_{2} z}\left\{\begin{array}{l}
C \\
D \\
G
\end{array}\right\} \\
+\frac{\mathrm{Be}^{\alpha_{1} z}}{k_{1}^{2}\left(1-\frac{\beta c}{\omega}\right)^{2}}\left\{\begin{array}{c}
-i \beta \\
-i \gamma \\
-\alpha_{1}
\end{array}\right\}+e^{\alpha_{2} z}\left\{\begin{array}{l}
E \\
F \\
H
\end{array}\right\}
\end{aligned}
$$

where A, B, C, D, E, F, G, H are depending on $\beta$ and $\gamma$. The constants $\mathrm{G}$ and $\mathrm{H}$ are calculated with the aid of the dilatation expression which gives :

$$
\left\{\begin{array}{l}
G=\frac{i}{\alpha_{2}}(\beta C+\gamma D) \\
H=-\frac{i}{\alpha_{2}}(\beta E+\gamma F)
\end{array}\right.
$$

and then the transformed displacements can be written with matrix expression as follows :

$$
\{\overline{\mathrm{U}}\}=[\mathrm{T}]\{\mathrm{A}, \mathrm{B}, \mathrm{C}, \mathrm{D}, \mathrm{E}, \mathrm{F}\}^{\mathrm{t}}
$$

with

$$
\{\bar{U}\}=\{\bar{u}(0), \bar{v}(0), i \bar{w}(0), \bar{u}(h), \bar{v}(h), i \bar{w}(h)\}^{t}
$$

Fourier transforming the stress-strain relations, the stresses in the wave number domain can be written in terms of the constants A, B, C, D, E and F :

$$
\{\bar{\Sigma}\}=[\mathrm{S}]\{\mathrm{A}, \mathrm{B}, \mathrm{C}, \mathrm{D}, \mathrm{E}, \mathrm{F}\}^{\mathrm{t}}
$$

with

$$
\{\bar{\Sigma}\}=\left\{-\overline{\sigma_{\mathrm{xz}}}(0),-\overline{\sigma_{\mathrm{yz}}}(0),-\mathrm{i} \overline{\sigma_{\mathrm{zz}}}(0), \overline{\sigma_{\mathrm{xz}}}(\mathrm{h}), \overline{\sigma_{\mathrm{yz}}}(\mathrm{h}), \overline{\mathrm{i}} \overline{\mathrm{zz}}(\mathrm{h})\right\}
$$

Combining (48) and (50), we obtain the following system :

$$
[\mathrm{S}][\mathrm{T}]^{-1}\{\overline{\mathrm{u}}\}=\{\bar{\Sigma}\}
$$

With the different choices made for the expressions of the vectors of displacements and strains, the final matrix $[\mathrm{S}][\mathrm{T}]^{-1}$ is symmetric.

For the numerical results, Figs 17 and 18 show the amplitude of vertical displacements along the line $\mathrm{y}=0$ for different layer's depths. Fig. 17 is obtained in the sub-Rayleigh case $\left(M_{R}=0.5\right)$ and Fig. 18 in the super-Rayleigh case $\left(M_{R}=2\right)$. 


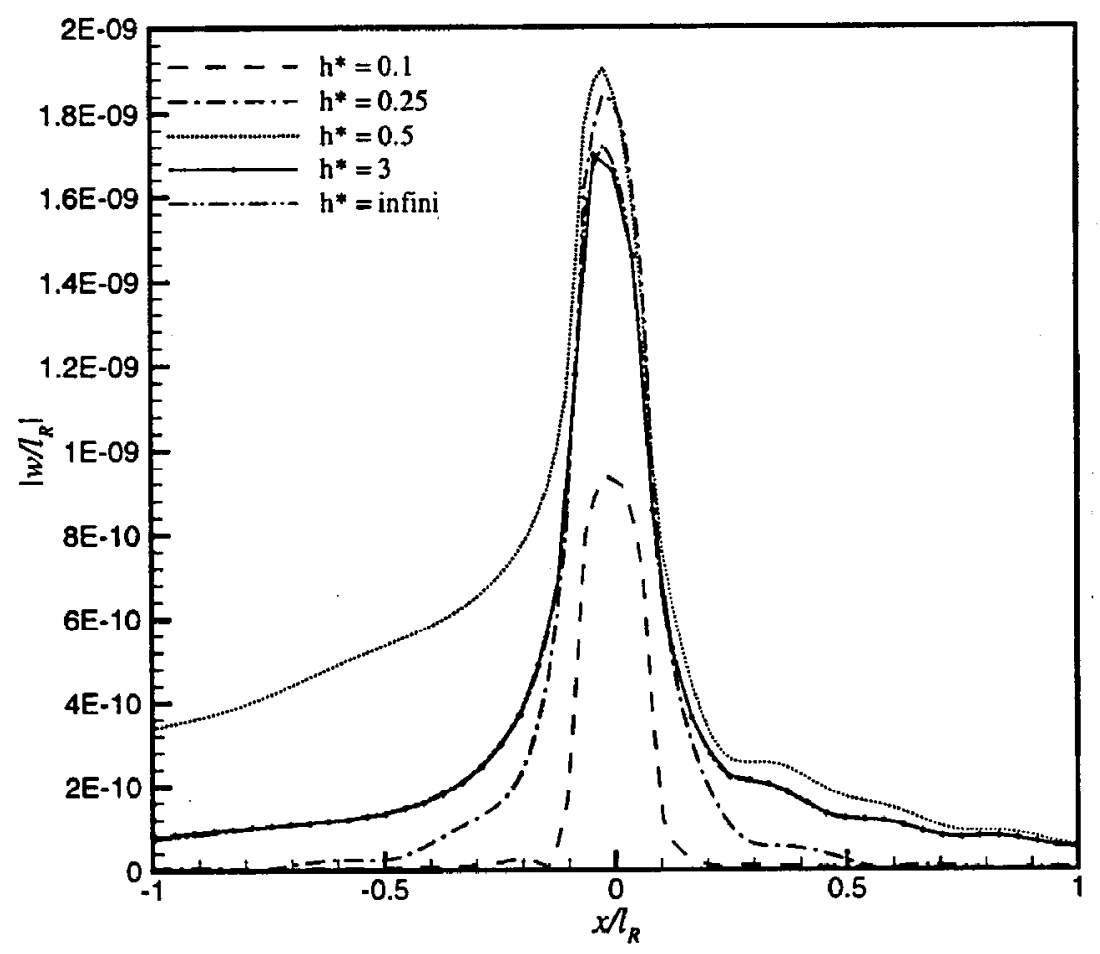

Fig. 17 - Vertical displacements for $\mathrm{M}_{\mathrm{R}}=0.5$.

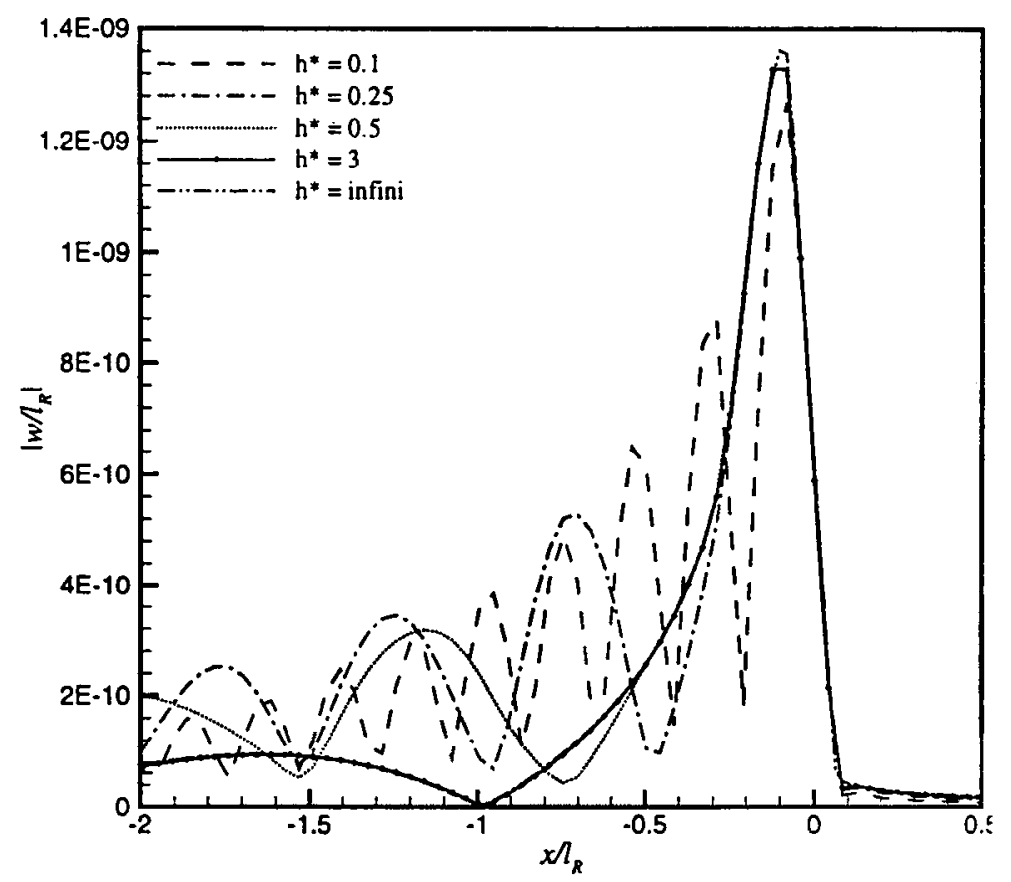

Fig. 18 - Vertical displacements for $\mathrm{M}_{\mathrm{R}}=2$.

In the first case, as for the 2D study (Figs 8 and 9), for a critical depth closed to 0.5 , the displacements are clearly higher, but mainly behing the load. Besides, except for $\mathrm{h}^{*}=0.1$, under the load $(\mathrm{x}=0)$, all maximum displacements are practically equal. Also, all curves are almost symmetric.

In the second case, we can see as usually the existence of disturbance and higher displacements behing the load. Then the condition $\mathrm{h}^{*}=0.5$ don't give the higher responses and consequently for the super-Rayleigh case it is difficult to take into account the critical depth. 


\subsubsection{Multilayered soils}

Now, the ground has several horizontal layers overlaying an elastic half-space. To obtain a solution of such a problem, we just have to combine the results of the two previous paragraphs (as for the 2D approach). We construct a global stiffness matrix using the same assembly process as in finite element analysis, (continuity of displacements and strains at each interface). Finally, using the continuity of displacements and strains at the interface between the last layer and the half-space, we obtain the following matrix system :

$$
\left[\begin{array}{c}
\text { global } \\
\text { stiffness } \\
\text { matrix }
\end{array}\right]\left\{\begin{array}{c}
\overline{\mathrm{u}}(0) \\
\overline{\mathrm{v}}(0) \\
\mathrm{i} \overline{\mathrm{w}}(0) \\
\ldots \ldots \ldots . . \\
2 \overline{\mathrm{u}}\left(\mathrm{h}_{\mathrm{k}}\right) \\
2 \overline{\mathrm{v}}\left(\mathrm{h}_{\mathrm{k}}\right) \\
2 \overline{\mathrm{w}}\left(\mathrm{h}_{\mathrm{k}}\right) \\
\ldots \ldots \ldots \ldots . . \\
2 \overline{\mathrm{u}}\left(\mathrm{h}_{\mathrm{n}}\right) \\
2 \overline{\mathrm{v}}\left(\mathrm{h}_{\mathrm{n}}\right) \\
2 \mathrm{i} \overline{\mathrm{w}}\left(\mathrm{h}_{\mathrm{n}}\right)
\end{array}\right\}=\left\{\begin{array}{c}
-\overline{\sigma_{\mathrm{xz}}}(0) \\
-\overline{\sigma_{\mathrm{yz}}}(0) \\
-\mathrm{i} \sigma_{\mathrm{zz}}(0) \\
\ldots \ldots \ldots \ldots . . \\
0 \\
0 \\
0 \\
\ldots \ldots \ldots \ldots . . \\
0 \\
0 \\
0
\end{array}\right\}
$$

yielding the transformed displacements at each interface. For the numerical analysis, for example two layers over an elastic foundation, the results can be deduced after a very long calculation, but are above all too complicated to explain the influence of characteristics concerning with the layers (material properties, depth, ...) and the load (frequency, speed particularly).

\section{APPLICATION TO RAILWAY TRAFFIC}

Previous studies are concerned with the dynamic behaviour of soil media for a moving harmonic loading. For the ground, a lot of models can be used : two- or threedimensional, half -space or multilayered soils. For a real excitation relative to the railway traffic, it is necessary to choose a more suitable model than a simple harmonic load.

\subsection{Description of the track}

Several track models have been already described in the literature. Some track models are based on Green's functions (Krylov [33]), others on a description in finite elements (Bode and Savidis [34]). Others models using the formalism of Fourier transform consider the discrete nature of the track due to sleepers spacing (Metrikine and Popp [35]) or assume the homogeneity and the continuity of the track lying on the ground (Sheng et al. [36]).

Our numerical model is built with a semi-analytical method for rail, pads and sleepers. In a range of low frequencies (below $80 \mathrm{~Hz}$ ), the track can be seen as a simple mass spring system. So the continuous track model used is shown in Figure 19. For the rail, the Euler beam theory is used. In front of the foreseen wavelengths, the sleepers are described as a 
continuous mass system. Pads and ballast have a visco-elastic damping with an arbitrary frequency dependence. Consequently, in this mass-spring system, waves generated in the rail transmit energy to the ground through the sleepers. Note that the reaction of the ground to sleepers is a dependent function of the frequency and interact with the track.

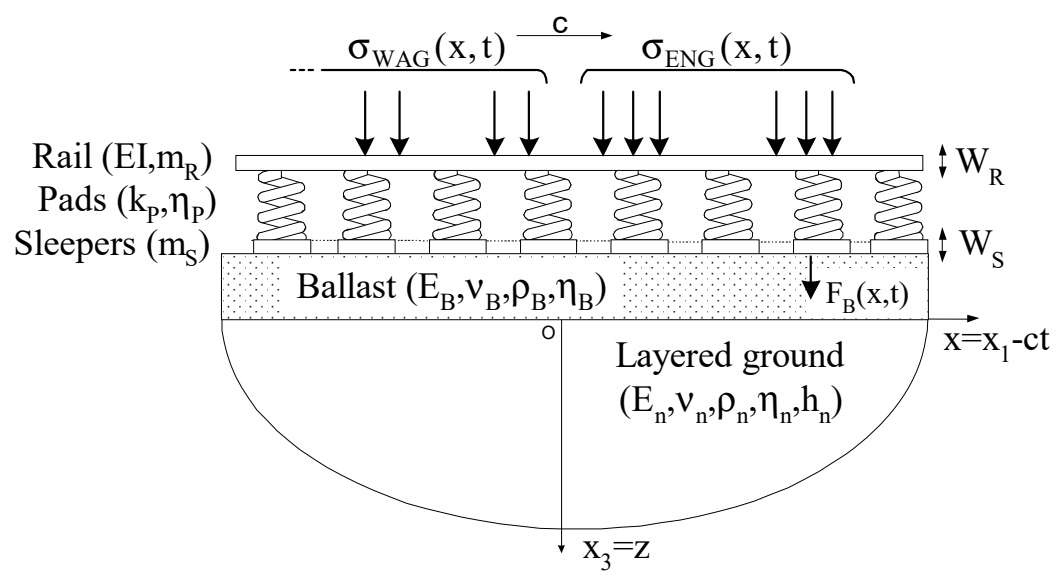

Fig. 19 - Track-Soil interaction model

In a two-dimensional or three-dimensional model the ballast can be described as the first layer of the soil. Also railpads and ballast can prove non linear properties in some ranges of frequencies. Several models ([37],[38]) tend to approach these effects.

To describe the rail [39], a mathematical model based on the Euler beam gives the following equation :

$$
\begin{aligned}
\mathrm{EI} \frac{\partial^{4} \mathrm{w}_{\mathrm{R}}\left(\mathrm{x}_{1}, \mathrm{t}\right)}{\partial \mathrm{x}_{1}^{4}}+\mathrm{m}_{\mathrm{R}} \frac{\partial^{2} \mathrm{w}_{\mathrm{R}}\left(\mathrm{x}_{1}, \mathrm{t}\right)}{\partial \mathrm{t}^{2}}+\mathrm{k}_{\mathrm{P}}\left[\mathrm{w}_{\mathrm{R}}\left(\mathrm{x}_{1}, \mathrm{t}\right)-\mathrm{w}_{\mathrm{S}}\left(\mathrm{x}_{1}, \mathrm{t}\right)\right]= \\
\left\{\begin{array}{rc}
\sigma_{\mathrm{TR} \text { AIN }}(\mathrm{x}, \mathrm{t}) & \text { if }\left|\mathrm{x}_{1}-\mathrm{ct}\right|<\mathrm{b} \\
0 & \text { else }
\end{array}\right.
\end{aligned}
$$

Besides, equation for sleepers is written :

$$
\mathrm{m}_{\mathrm{S}} \frac{\partial^{2} \mathrm{w}_{\mathrm{S}}\left(\mathrm{x}_{1}, \mathrm{t}\right)}{\partial \mathrm{t}^{2}}+\mathrm{k}_{\mathrm{P}}\left[\mathrm{w}_{\mathrm{S}}\left(\mathrm{x}_{1}, \mathrm{t}\right)-\mathrm{w}_{\mathrm{R}}\left(\mathrm{x}_{1}, \mathrm{t}\right)\right]=-\mathrm{F}_{\mathrm{S}}\left(\mathrm{x}_{1}, \mathrm{t}\right)
$$

where $\mathrm{w}_{\mathrm{R}}\left(\mathrm{x}_{1}, \mathrm{t}\right), \mathrm{w}_{\mathrm{S}}\left(\mathrm{x}_{1}, \mathrm{t}\right)$ are respectively the vertical displacements of the rail beam and the sleeper mass. $\mathrm{F}_{\mathrm{S}}\left(\mathrm{x}_{1}, \mathrm{t}\right)$ is the force per unit length of track between the sleeper and the ballast.

3.2. Two - dimensional problem (multilayered soil)

In this case, vertical and longitudinal transformed stresses are given by :

$$
\begin{aligned}
& \bar{\sigma}_{x z}=\mu\left(2 i \beta \frac{\partial \bar{\phi}}{\partial z}-\frac{\partial^{2} \bar{\psi}}{\partial z^{2}}-\beta^{2} \bar{\psi}\right) \quad \text { and } \\
& \bar{\sigma}_{z z}=(\lambda+2 \mu) \frac{\partial^{2} \bar{\phi}}{\partial z^{2}}-\lambda \beta^{2} \bar{\phi}+2 i \mu \beta \frac{\partial \bar{\psi}}{\partial z}
\end{aligned}
$$


where $\phi$ and $\psi$ are Helmoltz's potentials.

The resolution method is described in figure 20 where the fitted phase angle is defined relating to Helmoltz's potentials such as :

$$
\left\{\begin{array}{l}
\phi=\mathrm{Ae}^{\alpha_{1}(\mathrm{z}-\mathrm{h})}+\mathrm{Ce}^{-\alpha_{1} \mathrm{z}} \\
\psi=\mathrm{Be}^{\alpha_{2}(\mathrm{z}-\mathrm{h})}+\mathrm{De}^{-\alpha_{2} z}
\end{array}\right.
$$

where $\alpha_{i}=\sqrt{\beta^{2}-\frac{\Omega_{0}-\beta c}{c_{i}}}, i=1,2$.

$c_{1}(E, \rho, v)$ is the speed of compression waves (P-waves) and $c_{2}(E, \rho, v)$ is the speed of shear waves (S-waves).

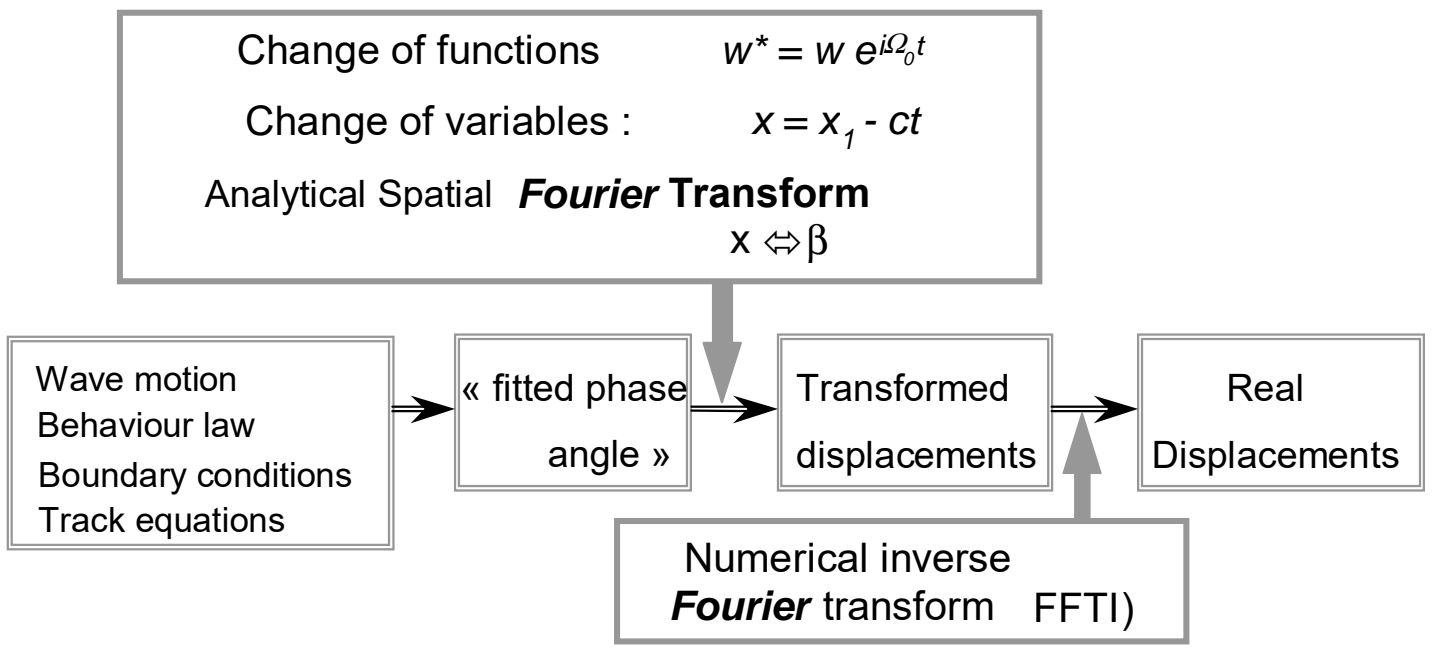

Fig. 20 - Resolution method

The application of this phase translation allows a good conditioning of the stiffness matrix of ground, then subsection of layers into sub - layers isn't necessary. A change of variables (translation in the mobile reference linked to the load) and functions (evaluation of the steady state solution) as well as the spatial Fourier transform allows the calculation of vertical displacement in the wave number domain.

Thus, for the ground, we can write a relationship between the displacement and stress for each layer interface (including the ballast) :

$$
\left[\begin{array}{cccccc}
\mathrm{T}_{11}^{\text {Bal }} & \mathrm{T}_{21}^{\text {Bal }} & \mathrm{T}_{31}^{\text {Bal }} & \mathrm{T}_{41}^{\text {Bal }} & 0 & 0 \\
\mathrm{~T}_{12}^{\text {Bal }} & \mathrm{T}_{22}^{\text {Bal }} & \mathrm{T}_{32}^{\text {Bal }} & \mathrm{T}_{42}^{\text {Bal }} & 0 & 0 \\
\mathrm{~T}_{13}^{\text {Bal }} & \mathrm{T}_{23}^{\text {Bal }} & \mathrm{T}_{33}^{\text {Bal }}+\mathrm{T}_{11}^{\mathrm{n}} & \mathrm{T}_{43}^{\text {Bal }}+\mathrm{T}_{21}^{\mathrm{n}} & \mathrm{T}_{31}^{\mathrm{n}} & \mathrm{T}_{41}^{\mathrm{n}} \\
\mathrm{T}_{14}^{\text {Bal }} & \mathrm{T}_{24}^{\text {Bal }} & \mathrm{T}_{34}^{\text {Bal }}+\mathrm{T}_{12}^{\mathrm{n}} & \mathrm{T}_{44}^{\text {Bal }}+\mathrm{T}_{22}^{\mathrm{n}} & \mathrm{T}_{32}^{\mathrm{n}} & \mathrm{T}_{42}^{\mathrm{n}} \\
0 & 0 & \mathrm{~T}_{13}^{\mathrm{n}} & \mathrm{T}_{23}^{\text {Bal }} & \mathrm{T}_{33}^{\mathrm{n}}+\mathrm{R}_{11} & \mathrm{~T}_{43}^{\mathrm{n}}+\mathrm{R}_{21} \\
0 & 0 & \mathrm{~T}_{14}^{\mathrm{n}} & \mathrm{T}_{24}^{\text {Bal }} & \mathrm{T}_{34}^{\mathrm{n}}+\mathrm{R}_{12} & \mathrm{~T}_{44}^{\mathrm{n}}+\mathrm{R}_{22}
\end{array}\right]\left\{\begin{array}{c}
\mathrm{i} \overline{\mathrm{w}}^{*}(0) \\
\overline{\mathrm{u}}^{*}(0) \\
\mathrm{i} \overline{\mathrm{w}}^{*}(\mathrm{~h}) \\
\overline{\mathrm{u}}^{*}(\mathrm{~h}) \\
\mathrm{i} \overline{\mathrm{w}}^{*}\left(\mathrm{~h}^{\mathrm{n}}\right) \\
\overline{\mathrm{u}}^{*}\left(\mathrm{~h}^{\mathrm{n}}\right)
\end{array}\right\}=\left\{\begin{array}{c}
-\mathrm{i} \overline{\mathrm{\sigma}}_{\mathrm{zz}}^{*}(0) \\
-\overline{\mathrm{\sigma}}_{\mathrm{xz}}^{*}(0) \\
0 \\
0 \\
0 \\
0
\end{array}\right\}=\left\{\begin{array}{c}
\mathrm{i} \overline{\mathrm{F}}_{\mathrm{S}}^{*}(\beta) \\
0 \\
0 \\
0 \\
0 \\
0
\end{array}\right\}
$$


where $\left[T_{B A L}\right]$ is the stiffness matrix of the ballast, $\left[T_{n}\right]$ is the stiffness matrix taking into account the $n$ layers of ground and $[R]$ is the stiffness matrix of the halfspace. The stiffness matrix $[T]$ is given by the product of the inverse of the displacement matrix [Q] by the stress matrix [S].

Thus, vertical displacements on the surface of the ballast and the ground can be written, respectively :

$$
\begin{aligned}
& \overline{\mathrm{w}}_{\mathrm{z}=0}^{*}(\beta)=[\mathrm{T}]_{11}^{-1} \overline{\mathrm{F}}_{\mathrm{S}}^{*}(\beta) \quad \text { and } \\
& \overline{\mathrm{w}}_{\mathrm{z}=\mathrm{h}}^{*}(\beta)=[\mathrm{T}]_{31}^{-1} \overline{\mathrm{F}}_{\mathrm{S}}^{*}(\beta)
\end{aligned}
$$

Assuming that the model for sleepers is continuous in front of the wavelength then we can obtain :

$$
\left\{\begin{array}{c}
\left.\left(E I \beta^{4}-\mathrm{m}_{\mathrm{R}} \Omega_{0}^{2}+\mathrm{k}_{\mathrm{P}}\right) \overline{\mathrm{w}}_{\mathrm{R}}^{*}(\beta)-\mathrm{k}_{\mathrm{P}} \overline{\mathrm{W}}_{\mathrm{S}}^{*}(\beta)\right]=\bar{\sigma}_{\mathrm{TR} \text { AIN }}(\beta) \\
-\mathrm{k}_{\mathrm{P}} \overline{\mathrm{w}}_{\mathrm{R}}^{*}(\beta)+\left(\mathrm{k}_{\mathrm{P}}-\mathrm{m}_{\mathrm{S}} \Omega_{0}^{2}\right) \overline{\mathrm{w}}_{\mathrm{S}}^{*}(\beta)=-\overline{\mathrm{F}}_{\mathrm{S}}^{*}(\beta) \\
\overline{\mathrm{w}}_{\mathrm{S}}^{*}(\beta)=[\mathrm{T}]_{11}^{-1} \overline{\mathrm{F}}_{\mathrm{S}}^{*}(\beta)
\end{array}\right.
$$

of which is deduced the displacement on the soil surface (below the ballast) :

$$
\overline{\mathrm{w}}_{\mathrm{z}=\mathrm{h}}^{*}(\beta)=[\mathrm{T}]_{31}^{-1} \frac{\mathrm{k}_{\mathrm{P}} \bar{\sigma}_{\mathrm{TR} \text { AIN }}(\beta)}{\left.\left[\left(\mathrm{EI} \beta^{4}-\mathrm{m}_{\mathrm{R}} \Omega_{0}^{2}+\mathrm{k}_{\mathrm{P}}\right)\left(\mathrm{k}_{\mathrm{P}}-\mathrm{m}_{\mathrm{S}} \Omega_{0}^{2}\right)-\mathrm{k}_{\mathrm{P}}^{2}\right] \mathrm{T}\right]_{11}^{-1}+\left(\mathrm{EI} \beta^{4}-\mathrm{m}_{\mathrm{R}} \Omega_{0}^{2}+\mathrm{k}_{\mathrm{P}}\right)}
$$

$\bar{w}_{z=h}^{*}(\beta)$ represents the vertical displacements in the wave number domain below the ballast (ground surface).

An analytic solution exists when the soil is considered as infinite in the positive zdirection. In this case, the Rayleigh's function leading to an infinite vertical displacement is determined by the cancellation of the denominator. It corresponds exactly to the speed of Rayleigh waves in the medium. In the case of a layered soil, displacements in the real numbers domain are calculated numerically by means of an inverse Fourier transform.

The vertical force exerted on the rail by a moving train is a complicated function of time. The spectrum of this function is wide but a significant part of the energy is concentrated between 0 and $20 \mathrm{~Hz}$. Besides, two components characterize the source of vibrations on the ground surface : a static component coming from the weight of axles of the train acting directly on the track and a dynamic component due to flaws of the track and wheels. For a simple wavelength of the rail, the train vibrates at the frequency $2 \pi \mathrm{c} / \lambda_{0}$ and each wheel exerts a vertical force $\mathrm{P}_{0} \mathrm{e}^{\mathrm{i} \Omega_{0^{\mathrm{t}}}}$. The rail is then constrained to its surface by a harmonic and moving function representing the train stress.

This function depends on the weight of each axle load, the excitation frequency $\Omega_{0}$ and the length parameters coming from bogies and axles. The railway train (engine and carriages) and its stress function are plotted in Figure 21. In the wave number, main peaks translate a frequency passage of a bogie or wheel. Finally this formulation is introduced in the model (at rail surface). 


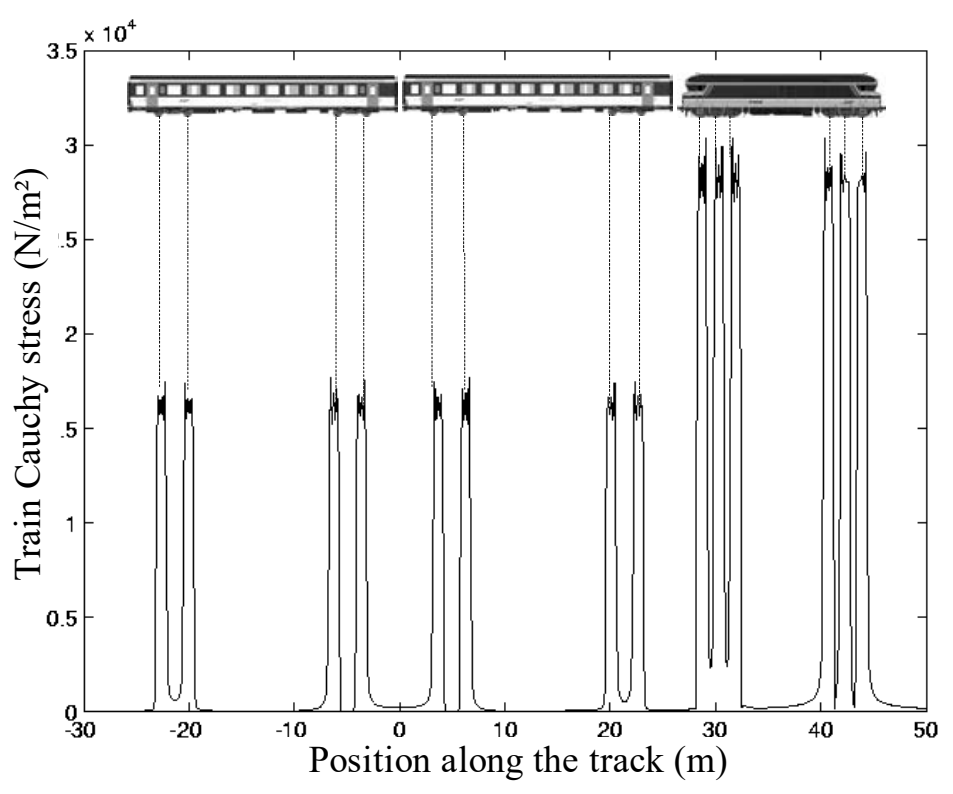

Fig 21- Railway excitation.

According to the Figure 21, the Cauchy stress due to the engine in the wave number domain can be written :

$$
\bar{\sigma}_{\mathrm{ENG}}(\beta)=-2 \mathrm{P}_{\mathrm{ENG}} \mathrm{e}^{\mathrm{i} \Omega_{0} \mathrm{t}} \mathrm{e}^{-\mathrm{i} \frac{\beta}{2}\left(\mathrm{~N}_{\mathrm{WAG}} \mathrm{L}_{\mathrm{WAG}}+\mathrm{L}_{\mathrm{ENG}}\right)} \frac{\sin \beta \mathrm{b}}{\beta \mathrm{b}} \times\left[1+2 \cos \beta \mathrm{L}_{\mathrm{BOG}-\mathrm{ENG}}\right] \cos \beta \mathrm{L}_{\mathrm{AX}-\mathrm{ENG}}
$$

and the Cauchy stress due to carriages :

$$
\bar{\sigma}_{\mathrm{WAG}}(\beta)=-4 \mathrm{P}_{\mathrm{WAG}} \mathrm{e}^{\mathrm{i} \Omega_{0} \mathrm{t}} \frac{\sin \beta \mathrm{a}}{\beta \mathrm{a}} \cos \beta \mathrm{L}_{\mathrm{AX}-\mathrm{ENG}} \times \cos \beta \mathrm{L}_{\mathrm{BOG}-\mathrm{WAG}} \sum_{\mathrm{k}=1}^{2 \mathrm{~N}_{\mathrm{WAG}}} \mathrm{e}^{\mathrm{i} \beta\left(\mathrm{k}-\frac{\mathrm{N}_{\mathrm{WAG}}}{2}-\frac{1}{2}\right) \mathrm{L}_{\text {WAG }}}
$$

such as

$$
\bar{\sigma}_{\mathrm{TR} A I N}(\beta)=\bar{\sigma}_{\mathrm{ENG}}(\beta)+\bar{\sigma}_{\mathrm{WAG}}(\beta) .
$$

$\bar{\sigma}_{\text {TR AIN }}(\beta)$ then represent the transformed stress exerted on the rail by the entire train.

For the numerical results, data for the ground are given in Table 3.

\begin{tabular}{|c|c|c|c|c|c|c|c|}
\hline & $\mathrm{h}(\mathrm{m})$ & $\mathrm{E}\left(\mathrm{N} / \mathrm{m}^{2}\right)$ & $v$ & $\rho\left(\mathrm{kg} / \mathrm{m}^{3}\right)$ & $\eta$ & $\mathrm{c}_{\mathrm{P}}(\mathrm{m} / \mathrm{s})$ & $\mathrm{c}_{\mathrm{S}}(\mathrm{m} / \mathrm{s})$ \\
\hline Ballast & 0,8 & $300 \times 10^{6}$ & 0.3 & 1800 & 0.1 & 547 & 292 \\
\hline Layer & 7 & $269 \times 10^{6}$ & 0.257 & 1550 & 0.1 & 459 & 263 \\
\hline Substratum & $\infty$ & $2040 \times 10^{6}$ & 0.179 & 2450 & 0.1 & 950 & 594 \\
\hline
\end{tabular}

Table 3 - Parameters for numerical investigation

In these conditions, the critical speed is close to 100 metres per second. Rails Young's modulus is equal to $2,11.10^{11} \mathrm{~N} / \mathrm{m}^{2}$, the moment of inertia to $3055 \mathrm{~cm}^{4}$ and the mass per unit of track length to $120 \mathrm{~kg} / \mathrm{m}$. The stiffness of the pads between the rail and sleepers is equal to $3,5 \cdot 10^{8} \mathrm{~N} / \mathrm{m}$ with a damping coefficient equal to 0,15 . The mass of wooden sleepers per unit 
of track length is equal to $490 \mathrm{~kg} / \mathrm{m}$. The ballast is a stiff layer compared to the soft peat with a Young's modulus equal to $400.10^{6} \mathrm{~N} \cdot \mathrm{m}^{-2}$, a Poisson ratio equal to 0.3 and a density equal to $1800 \mathrm{~kg} / \mathrm{m}^{3}$. Damping is assumed to be hysteretic with a factor equal to 0.1 .

Figure 22 shows a comparison between the displacements in the real domain for each speed regime : static, sub-Rayleigh and super-Rayleigh passing through the critical speed. The excitation frequency is chosen equal to $10 \mathrm{~Hz}$ according to real train spectra. The Sub-Rayleigh speed is equal to $0.5 \times c_{R}$ and the super-Rayleigh speed to $1.5 \times c_{R}$ where $c_{R}$ is the speed of the Rayleigh wave. All results are divided by the Rayleigh wavelength $\lambda_{R}$ for non-dimensional study. For non moving load, displacements are distributed symmetrically in the front and behind the load. Increase of speed involves increasing of vertical displacements amplitude and then the increase of the wavelength and oscillation behind the load. Increase of vibration can be noted for super-Rayleigh regime.

Besides, in super-Rayleigh regime, when the train speed on track exceeds the Rayleigh wave speed at the soil surface, Mach cones appear on the soil for each bogie load. So, Mach cones due to $\mathrm{P}$ and S-waves can be found below the surface and Mach cone due to Rwaves at the soil surface.

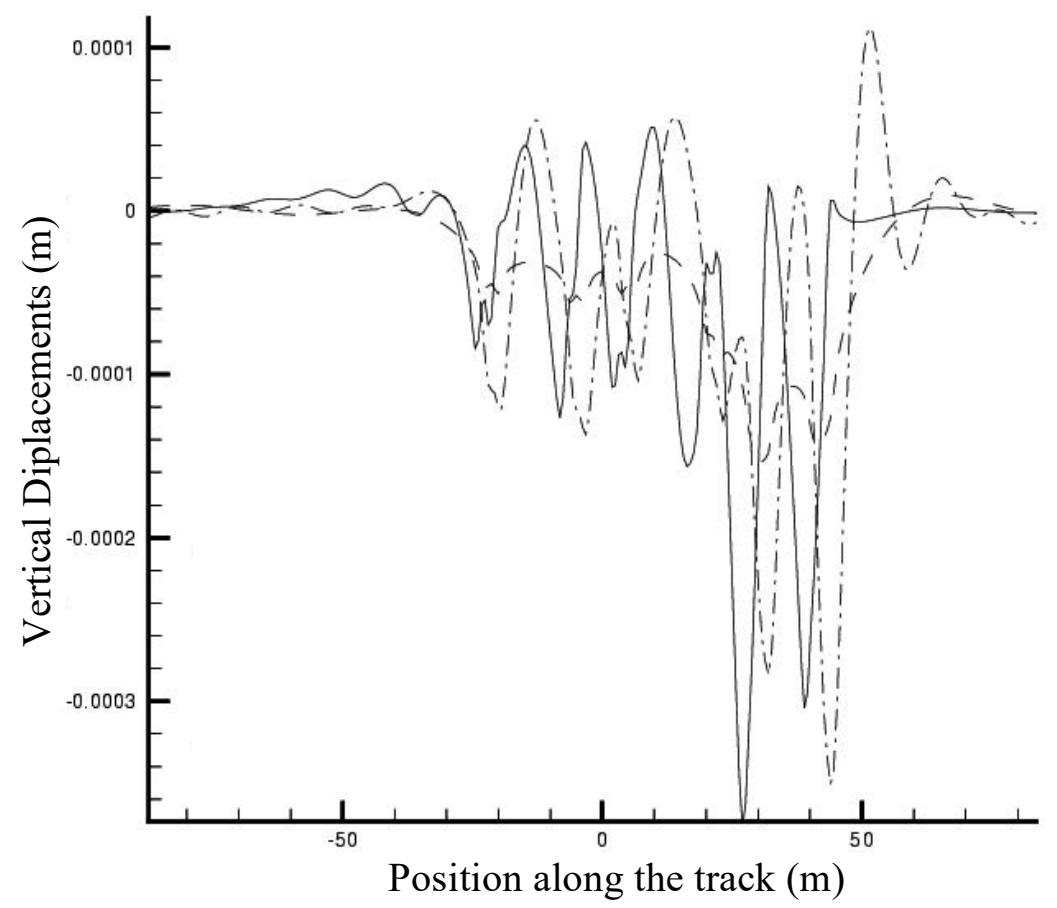

Fig. 22 - Maximum vertical displacements

at the soil surface near the track for current train

( $c=0:$ dashed line, $c=0.5 \times c_{R}:$ dash-dotted line, $c=1.5 \times c_{R}:$ solid line).

Also, the mutual interaction between the engine, the carriage and the track was studied Hung and Yang [40], Wu and Shih [41] for example.

\subsection{Three-dimensional problem}

Then, the ground is modelled by either a half-space or a multilayered soil including or not the ballast. For the resolution and calculation of surface displacements, we combine the previous approaches taking into account the train, track and ground models, and the classical 
methods (change of variables, Fourier transform, choice of « fitted phase argument », numerical inverse Fourier transform). Here, we limit the presentation to some numerical results. For example, Fig. 23 gives the vertical surface displacements obtained for an unit load (frequency equal to $40 \mathrm{~Hz}$ ) moving on a track connected with a ground constituted by an elastic sandy layer and a half-space.

Fig. 23 - Vertical surface displacements for a layered soil (static, sub-Rayleigh and super-Rayleigh regimes respectively).

Similarly, Fig. 24 shows the vertical surface displacements deduced for a Corail train. In this case, the frequency is equal to $10 \mathrm{~Hz}$, the ballast is modelled as the first layer of soil, and the ground is constituted by a peaty material.

Fig. 24 - Vertical surface displacements for a Corail train (on the left : sub-Rayleigh regime, on the right : super-Rayleigh regime).

We confirm the previous results obtained at the ground surface for various speeds. Particularly, increase of speed implies more important vertical displacements and oscillations behind the train. Besides, we can see the Mach cones for each bogie group.

CONCLUSIONS 


\section{REFERENCES}

[1] Picoux B., Le Houédec D.

«Propagation dans le sol des vibrations émises par un véhicule ferroviaire se déplaçant à vitesse constante » (in French) - Rapport PREDIT, Aide n DGAD/SRAE/99107, 2002.

[2] Madshus C., Kaynia A.

«High speed railvay lines on soft ground: dynamic behaviour at critical train speed » Journal of Sound and Vibration, 231 (3), 689-701, 2000.

[3] Eason G., Fulton J., Sneddon I.

«Generation of waves in an infinite elastic solid by variable body forces », Philos. Trans. Roy. Soc., vol. A 248, 575-607, 1956.

[4] Eason G.

« The stress produced in a semi-infinite solid by moving surface force »

Int. Journ. Eng. Sc., vol. 2, 581-609, 1965.

[5] Cole J., Huth J.

«Stresses produced in a half-plane by moving loads », Journ. Appl. Mech., 25, 433-436, 1958.

[6] Georgiadis H., Barber J.

«Steady-state transonic motion of a line load over an elastic half-space : the corrected Cole-Huth solution « Journ. Appl. Mech., 60, 772-774, 1993.

[7] Fryba L.

«Vibrations of solids and structures under moving loads » Mechanics of Structural Systems, Groningen, Noordhoff, 1972.

[8] Niwa Y., Kobayashi S.

« Stresses produced in an elastic half-plane by moving loads along its surface », 254-276, 1966.

[9] Alabi B.

«Ground vibration excited by surface trains », The Nigerian Engineer, vol. 23, 1-10, 1988.

[10] Jones D., Le Houédec D., Peplow A., Petyt M.

" Ground vibration in the vicinity of a moving harmonic rectangular load on a half-space », European Journal of Mechanics A/Solids, vol. 17, n¹, 153-166, 1998.

[11] Keer L.

« Moving and simultaneously fluctuating loads on an elastic half-plane », Journ. Acoust. Soc. Am., 47, 1359-1365, 1969.

[12] Gunaratne M., Sanders O.

« Response of a layered elastic medium to a moving strip load », Int. Journ. Numer. Anal. Meth. Geomech, 20, 191-208, 1996.

[13] Lefeuve-Mesgouez G., Peplow A., Le Houédec D., Jones D.

«Ground vibration due to a high -speed moving harmonic load », $12^{\text {th }}$ Engineering Mechanics ASCE Conference, La Jolla (California), 17-20 May, Proceedings CD-ROM (4 pages), 1998.

[14] De Barros F., Luco J.

« Stresses and displacements in a layered half-space for a moving line load », Appl. Math. Comput., 67, 103-134, 1995.

[15] Lefeuve-Mesgouez G., Le Houédec D., Peplow A.

"Ground vibration in the vicinity of a high-speed moving harmonic strip load», Journal of Sound and Vibration, 231(5), 1289-1309, 2000.

[16] Payton R.

«Transient motion of an elastic half-space due to a moving surface line load», Intern. Journ. Engng Sci., 5, 49-79, 1967. 
[17] Lansing D.

«The displacements in an elastic half-space due to a moving concentrated normal load », NASA Technical Report, TR R-238, 1966.

[18] Alabi B.

« A model for the problem of ground vibration induced by the wheels of a moving train », Appl. Math. Model., 13, 710-715, 1989.

[19] Alabi B.

«A parametric study on some aspects of ground-borne vibrations due to rail traffic », Journal of Sound and Vibration, 153, 77-87, 1992.

[20] De Barros F., Luco J.

« Response of a layered viscoelastic half-space to a moving point load », Wave motion, 19, 189-210, 1994.

[21] Krylov V.

«Generation of ground vibrations by superfast trains », Applied Acoustics, 44, 149-164, 1995.

[22] Lefeuve-Mesgouez G., Le Houédec D., Peplow A.

"Ground vibration due to a high-speed moving harmonic load», $4^{\text {th }}$ Conference EURODYN, 7-10 June, Praha, A.A. Balkema Structural Dynamics, vol. 2, 963-968, 1999.

[23] Lefeuve-Mesgouez G., Peplow A, Le Houédec D.

"Surface vibration due to a sequence of high speed moving harmonic rectangular loads », Soil Dynamics and Earthquake Engineering, 22, 459-473, 2002.

[24] Brigham E.

«The Fast Fourier Transform », Englewood Cliffs, N.J., Prentice-Hall, 1974.

[25] Le Houédec D.

«Réduction et propagation dans le sol des vibrations dues au trafic routier urbain : cas particulier des chaussées sur fondation élastique »(in French), Thèse de Doctorat-èsSciences, Ecole Centrale de Nantes, 1980.

[26] Ewing W., Jardetzky W., Press F.

«Elastic waves in layered media », Mc Graw-Hill, New-York, 1957.

[27] Morse P., Ingard K.

«Theoretical Acoustics », Mc Graw-Hill, New-York, 1986.

[28] Jones D., Petyt M.

"Ground vibration in the vicinity of a strip load : an elastic layer on a rigid foundation », Journal of Sound and Vibration, 152(3), 501-515, 1992.

[29] Waas G.

«Linear two-dimensional analysis of soil dynamics problems in semi-infinite layered media », Ph. D. thesis, University of California, Berkeley, 1972.

[30] Laghrouche O.

«Simulation numérique de propagtion d'ondes dans les sols - Application à l'isolation vibratoire » (in French), Thèse de Doctorat, Ecole Centrale de Nantes, 1996.

[31] Jones D., Petyt M.

"Ground vibration in the vicinity of a rectangular load on a half-space », Journal of Sound and Vibration, vol. 166, $\mathrm{n}^{\circ} 1,141-159,1993$.

[32] Thomson W., Kobori T.

« Dynamical compliance of rectangular foundations on an elastic half-space », Journal of Applied Mechanics, 579-584, 1963.

[33] Krylov V.

« Spectra of low frequency ground vibrations generated by high speed trains on layered ground », Journal of Low Frequency Noise Vibration and Active Control », 16(4), 257-270, 1997. 
[34] Bode C., Savidis S.

" Three dimensional time analysis of moving loads on railway tracks on layered soils ", Wave 2000, Proceedings A.A. Balkema, 3-12, Chouw and Schmid (Eds), 2000.

[35] Metrikine A., Popp K.

"Vibration of a periodically supported beam on an elastic half-space », European Journal of Mechanics A/Solids, 18, 679-701, 1999.

[36] Sheng X., Jones D., Petyt M.

«Ground vibration generated by a load moving along a railway track », Journal of Sound and Vibration, 228(1), 129-156, 1999.

[37] Suiker A., Metrikine A., De Borst R.

«Dynamic behaviour of a layer of a discrete particles - Part 2 : Response to an uniformly moving, harmonically vibrating load », Journal of Sound and Vibration, 240(1), 19-39, 2001.

[38] Nguyen V.

« Comportement dynamique de structures non-linéaires soumises à des charges mobiles » (in French), Thèse de Doctorat, Ecole Nationale des Ponts-et-Chaussées, 2002.

[39] Jones D., Sheng X., Petyt M.

«Simulation of ground vibration from a moving harmonic load on a railway track », Journal of Sound and Vibration, 231(3), 739-751, 2000.

[40] Hung H., Yang Y.

«Elastic waves in visco-elastic half space generated by various vehicle loads », Soil Dynamics and Earthquake Engineering, 21, 1-17, 2001.

[41] Wu J., Shih P.

«Dynamic responses of railway and carriages under the high speed moving loads », Journal of Sound and Vibration, 236(1), 61-87, 2000.

\section{ADDITIF}

\section{- G. LEFEUVE-MESGOUEZ, A.T. PEPLOW, D. LE HOUÉDEC}

«Surface vibration due to a sequence of high speed moving harmonic rectangular loads » Soil Dynamics and Earthquake Engineering, 22 (2002), pp. 459-473.

\section{- B. PICOUX, D. LE HOUÉDEC}

«Etude théorique et expérimentale de la propagation des vibrations émises par un trafic ferroviaire se déplaçant à vitesse constante », Journal de Physique IV, 12 (2002), pp. 111-118.

- B. PICOUX, R. ROTINAT, J.P. REGOIN, D. LE HOUÉDEC, F. QUÉTIN, J.P. HAMELIN « Modèle prédictif de propagation des vibrations à partir de véhicules ferroviaires se déplaçant à vitesse constante $»$, Acoustique et Techniques, 2002, n 30, pp. 4-7.

\section{- D. LE HOUÉDEC, F. KRÜGER, M. HECHT}

Séminaire franco-allemand « Transport silencieux », Programme de recherche « Mobilität und Verkehr », Bonn, 17-18 juin 2003, Animation de la table ronde sur la réduction du bruit ferroviaire. 
- $9^{\text {th }}$ International Conference on Civil and Structural Engineering Computing,

Egmond ann Zee (Netherlands), 2-4 September 2003.

* Special lecture (invited paper) : D. LE HOUÉDEC, B. PICOUX

«Soil-structure interaction for moving loads : application to railway traffic »

* Communication orale : B. PICOUX, D. LE HOUÉDEC

« Numerical and experimental comparison of D-model for the study of railway vibrations »

* Organisation de la session spéciale « Dynamics of structures for moving loads » (une douzaine de présentations). 